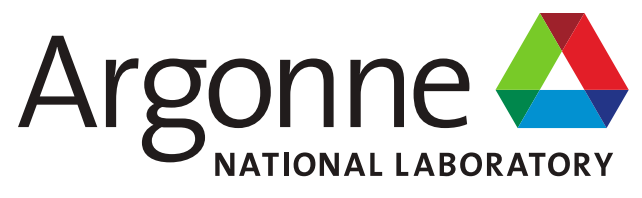

\title{
Involute Working Group - FSI Analysis of Fuel Plates Using Finite Volume and Finite Element Methods
}

Nuclear Science \& Engineering Division 


\title{
About Argonne National Laboratory
}

Argonne is a U.S. Department of Energy laboratory managed by UChicago Argonne, LLC under contract DE-AC02-06CH11357. The Laboratory's main facility is outside Chicago, at 9700 South Cass Avenue, Argonne, Illinois 60439. For information about Argonne and its pioneering science and technology programs, see www.anl.gov.

\section{DOCUMENT AVAILABILITY}

Online Access: U.S. Department of Energy (DOE) reports produced after 1991 and a growing number of pre-1991 documents are available free at OSTI.GOV (http://www.osti.gov/), a service of the U.S. Dept. of Energy's Office of Scientific and Technical Information.

\author{
Reports not in digital format may be purchased by the public from the \\ National Technical Information Service (NTIS): \\ U.S. Department of Commerce \\ National Technical Information Service \\ 5301 Shawnee Rd \\ Alexandria, VA 22312 \\ www.ntis.gov \\ Phone: (800) 553-NTIS (6847) or (703) \\ 605-6000 Fax: (703) 605-6900 \\ Email: orders@ntis.gov
}

\section{Reports not in digital format are available to DOE and DOE contractors from the Office of Scientific and Technical Information (OSTI):}

U.S. Department of Energy

Office of Scientific and Technical Information

P.O. Box 62

Oak Ridge, TN 37831-0062

www.osti.gov

Phone: (865) 576-8401

Fax: (865) 576-5728

Email: reports@osti.gov

Disclaimer

\section{Disclaimer}

This report was prepared as an account of work sponsored by an agency of the United States Government. Neither the United States Government nor any agency thereof, nor UChicago Argonne, LLC, nor any of their employees or officers, makes any warranty, express or implied, or assumes any legal liability or responsibility for the accuracy, completeness, or usefulness of any information, apparatus, product, or process disclosed, or represents that its use would not infringe privately owned rights. Reference herein to any specific commercial product, process, or service by trade name, trademark, manufacturer, or otherwise, does not necessarily constitute or imply its endorsement, recommendation, or favoring by the United States Government or any agency thereof. The views and opinions of document authors expressed herein do not necessarily state or reflect those of the United States Government or any agency thereof, Argonne National Laboratory, or UChicago Argonne, LLC. 


\section{Involute Working Group - FSI Analysis of Fuel Plates Using Finite Volume and Finite Element Methods}

prepared by

M. Sitek, C. Bojanowski, A. Bergeron, J. Licht

Nuclear Science \& Engineering Division, Argonne National Laboratory

November 2021 
(This page left intentionally blank) 


\section{Executive Summary}

The three involute plate research reactors RHF, HFIR, and FRM II have expressed an interest in using computational software to carry their steady-state safety analysis. Since these tools represent a significant departure from the methods used currently (one-dimensional), the acceptability of the new approach by regulators requires thorough verification and validation of these tools. Therefore, Argonne National Laboratory and the three involute-plate reactors formed an informal group called the Involute Working Group aiming at qualifying computational tools to perform steady-state safety analysis.

The present report focuses on a comparison of finite volume and finite element methods to model solids in fluid-structure interaction problems with the goal to estimate the coolant flow-induced fuel plate deflections obtained with the two methods. The finite volume method will be obsoleted in STAR$\mathrm{CCM}+$ by the end of 2021, nevertheless, this evaluation is important because the method was used by ANL researchers to model the response of the fuel plates, despite its drawbacks, which are discussed in the report. It was essential to check how those estimates compare to the results obtained with the finite element method that is considered superior for structural analysis.

Various geometries, i.e., flat, cylindrical and circle-involute fuel plates, as well as coolant flow speed, were considered. The comparison shows that, independently of the plate geometry, the finite volume method significantly underestimates the deflection as compared to finite element method for coarser meshes. When the discretization is developed as a result of a mesh sensitivity study using finite element method, the result obtained using finite volume method can be a few times smaller than the corresponding finite element method solution.

A code-to-code comparison, between STAR-CCM+ and LS-DYNA was included in the analysis. Within the LS-DYNA models, two types of finite element formulations were used: solid and shell finite elements. Mesh sensitivity study showed that both approaches converge to a similar value that was obtained with STAR-CCM+ finite element solver.

The evaluation of the computational solvers was extended by adding two benchmark cases from the STAR-CCM+ Verification Suite and presented in the Appendix A. The selected cases are: (1) bending of a cantilever beam under external load, and (2) cylindrical shell deformation analysis, known in the literature as 'Scordelis-Lo roof'. The problems were solved with finite volume, and finite element methods, and the results confirmed the previously discussed findings.

The analysis shows that the finite element solver is superior to the finite volume solver in terms of representation of model geometry and estimating the structural behavior of fuel plates. Depending on the ratio of the load to the flexibility of the plate, the finite volume solver can greatly under- or overestimate the structural response if a very carefully selected mesh is not used. 


\section{Table of Contents}

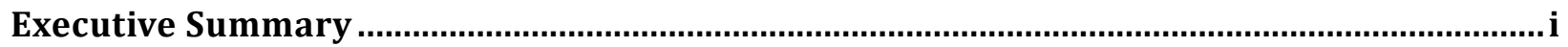

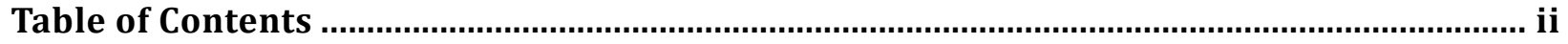

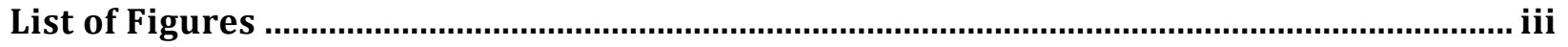

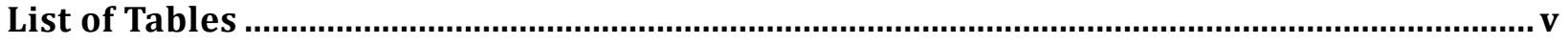

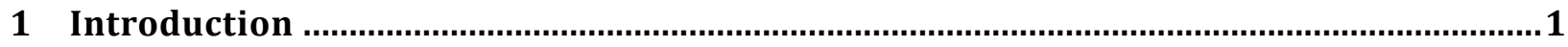

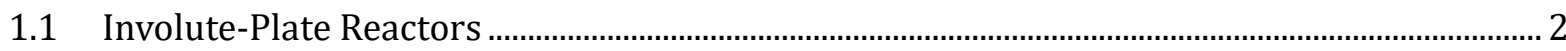

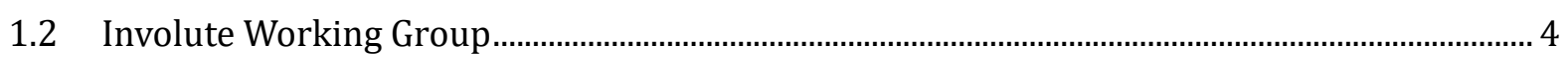

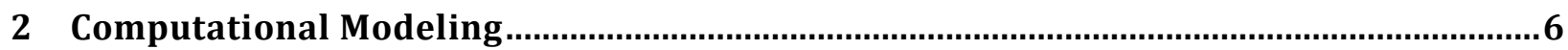

2.1 Finite Volume vs. Finite Element Methods for Modeling Thin Structures in Bending ........... 6

2.2 Fluid-Structure Interaction Analysis................................................................................................... 7

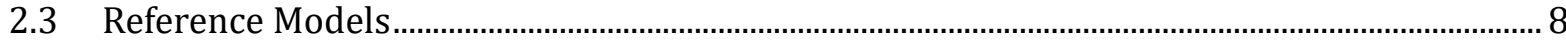

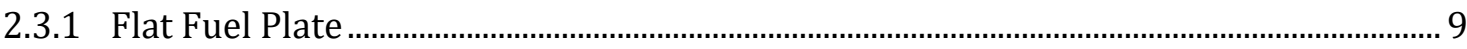

2.3.2 Cylindrical Plate.............................................................................................................

2.3.3 Involute Plate ........................................................................................................................ 12

3 Comparison of Fuel Plate Deflections Modeled with Different Solvers ......................... 16

3.1 Flat Fuel Plate .............................................................................................................................

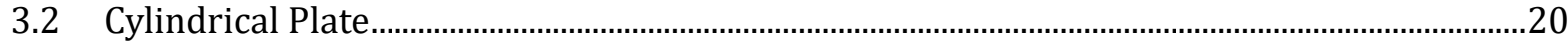

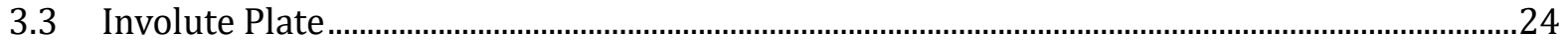

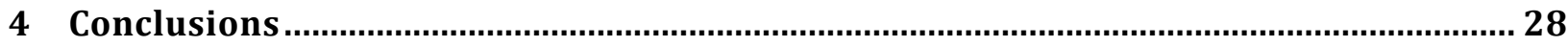

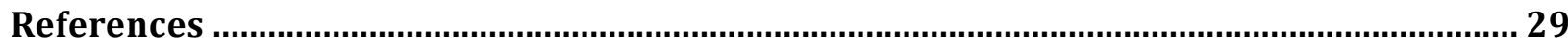

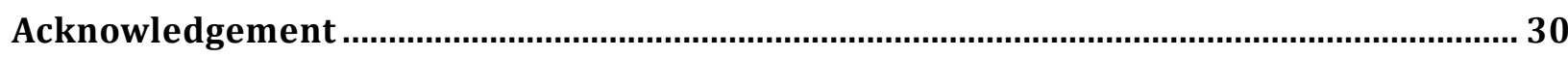

APPENDIX A: Verification Test Cases........................................................................................ 31

A.1 SM-1. Finite Element Bending of a Cantilever Beam ......................................................................... 31

A.2 SM-2. Scordelis-Lo Roof ……….............................................................................................................. 


\section{List of Figures}

Figure 1.1. From left to right, top view of the HFIR, RHF, and FRM II fuel elements (close to true proportionality).

Figure 1.2. View of RHF fuel plates curved as involute and welded between the two annular sideplates (picture taken from a mockup and not a real element, finish is therefore not representative of a real element).

Figure 1.3. Sketch of the involute fuel plates installed in the side plates. Note that the shape of the plates guarantees a constant coolant channel thickness. 3

Figure 2.1. Finite volume cell with a node in the cell centroid (left), an 8-node finite element Hex8 (center) and a 20-node finite element Hex20 (right). 7

Figure 2.2. Sketch of an example CFD model of a flat plate between two channels and additional plenum upstream and downstream of the plate. 8

Figure 2.3. An example discretization of the computational domain. ……................................................... 9

Figure 2.4. Sketch and dimensions of the flat fuel plate model. ..................................................................10

Figure 2.5. Deflection along the symmetry line of the $1.06 \mathrm{~mm}$ plate and $8 \mathrm{~m} / \mathrm{s}$ average channel flow velocity obtained with the use of STAR-CCM+ finite volume solver and co-simulation approach with ABAQUS [5].

Figure 2.6. Geometry of the CFD model with a cylindrical fuel plate, (a) top view, (b) perspective view.

Figure 2.7. Deflection of the tip of the $0.4 \mathrm{~mm}$-thick plate computed with the use of the finite volume and finite element solid stress solver in STAR-CCM+, and co-simulation technique between STARCCM+ and ABAQUS [5]. 12

Figure 2.8. Geometry of the involute plate model used in a previous study [15]. 14

Figure 2.9. Displacements in the involute plate model (a) view of the leading edge, (b) view of the convex surface of the plate [15]....

Figure 3.1. Pressure differential on the centerline of a flat fuel plate for varying Hex8 finite element mesh density, (a) along the full length of the plate, (b) close-up view of the leading edge. ( $w$ - wide channel side, $\mathrm{n}$ - the narrow channel side).

Figure 3.2. Convergence of the maximum deflection of a flat fuel plate modeled with solid finite elements.

Figure 3.3. Convergence of the maximum deflection of a flat fuel plate modeled with solid finite volumes.

Figure 3.4. Convergence of the maximum deflection of a flat fuel plate modeled with solid finite elements and finite volumes as a function of the number of degrees of freedom.

Figure 3.5. Example deflection contour plot of a cylindrical plate.

Figure 3.6. Relationship between the maximum deflection of the cylindrical plate and average channel velocity for varying plate thickness.

Figure 3.7 Comparison of the ratio of the maximum cylindrical plate deflection to plate thickness obtained with finite element and finite volume solvers (a) full range of values, (b) close-up to the 0 to 0.05 range. Dashed line is identity line... 23

Figure 3.8. Geometry of the involute plate model. .24 
Figure 3.9. Convergence of finite element and finite volume meshes for an involute plate as a function of the number of degrees of freedom along arc length of involute plate.....................................................25

Figure 3.10. Example deflection contour plot of an involute plate. ……......................................................25

Figure 3.11 Comparison of the maximum involute plate deflection presented in [15] and obtained in the current study

Figure 3.12. Comparison of the ratio of the maximum involute plate deflection to plate thickness obtained with finite element and finite volume solvers. Dashed line is identity line.

Figure A.2. Displacement field $U_{\text {Yloc }}$ of an elastic cantilevered beam modeled with Hex20 finite elements in structural mechanics case SM-1 (the deformation was scaled up to improve the readability of the figure)

Figure A.3. Axial stress $S_{x x}$ field in an elastic cantilevered beam modeled with Hex20 finite elements in structural mechanics case SM-1 (the deformation was scaled up to improve the readability of the figure).

Figure A.5. Vertical displacement of the roof modeled with Hex8 finite elements for case SM-2 (the deformation was scaled up to improve the readability of the figure). 


\section{List of Tables}

Table 1.1. Key parameters of fuel elements in involute reactors. .................................................................. 4

Table 1.2. Key thermal-hydraulic parameters in involute reactors................................................................... 4

Table 2.1. Dimensions of the flat fuel plate model...................................................................................

Table 2.2 Dimensions of the cylindrical plate model.

Table 2.3. Dimensions of the involute plate model....................................................................................14

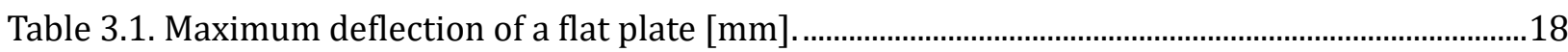

Table 3.2. Maximum deflection of a cylindrical plate .................................................................................2

Table 3.3. Convergence of the maximum deflection of an involute plate in STAR-CCM+......................24

Table 3.4. Maximum deflection of an involute plate...........................................................................................26 


\section{Introduction}

There are three research reactors in the world having fuel plates curved as circle-involute (a spiral generated around a circle):

- The Oak Ridge National Laboratory (ORNL) High Flux Isotope Reactor (HFIR) located in Tennessee, U.S.A. [1],

- The Laue-Langevin Institute (ILL) High Flux Reactor (RHF) located in Grenoble, France [2],

- The Technical University of Munich (TUM) Research Neutron Source Heinz Maier-Leibnitz (FRM II) located in Garching, Germany [3]

All three reactors are currently using Highly Enriched Uranium (HEU, ${ }^{235} \mathrm{U} / \mathrm{U} \geq 20 \mathrm{wt}$. \%) as fuel and all three are actively engaged in activities to convert to Low-Enriched Uranium (LEU, 235U/U $<20$ wt. \%) fuel. More information on these reactors can be found in Section 1.1.

Conversion of these reactors to LEU fuel requires internal and external changes to the fuel plate dimensions. In the early design stage, it is important to verify that the proposed LEU fuel plates will maintain their mechanical integrity during operation. Plate deflections are induced by a pressure difference between the concave and convex surfaces of the plate, among others, which is a result of a difference in neighboring channels thicknesses. Three-dimensional computational analysis was selected to model the plate's response to the pressure differential. Various open-source and commercial software that has capabilities to model fluid-structure interaction (FSI) is utilized by the researchers. Before it can be used to redesign the reactor fuel plates, a solid justification on the appropriateness of the codes is required. To accomplish this, Argonne National Laboratory (ANL or simply Argonne) and operators of the three involute reactors formed an informal group - the Involute Working Group (IWG). Activities of the group include benchmarking, code-to-code comparison, verification and validation $(V \& V)$ as well as technical support. More information on the IWG can be found in Section 1.2.

Up until 2015, finite volume method (FVM) was the only available solver to be used for computational solid mechanics in Simcenter STAR-CCM+ [4]. Finite element method (FEM) was implemented into the code in version 10.04, and the method is under active development with new features released in each consecutive version of the code. At the end of February 2021, it was announced that the Finite Volume Stress solver was going to be deprecated, and as of the 2021.1 release, it will no longer be supported. Moreover, as of the last release of the year 2021 (version 2021.4), the Finite Volume Stress solver will no longer be available in the code. With the development of the new capabilities provided by the developers of the software, there has been a transition from finite volume to finite element modeling of solids within the Star-CCM+ framework. Several studies were performed with the use of the new computational tool, which proved to be efficient.

This report covers a comparison of the estimates of the maximum fuel plate deflections due to hydrodynamic loading obtained with the use of finite volume method and finite element method to model the solid. Simulations are performed for various plate geometries and flow conditions. Three shapes of fuel plates are considered: a flat plate, a cylindrical plate, and an involute plate. The analysis covers a mesh sensitivity study to assess the convergence of the two methods in STAR-CCM+. Also, a code-to-code comparison of results with LS-DYNA software is included. 
Material properties of aluminum, with linear elastic relationship between strains and stresses, are assigned to the plate. The coolant is incompressible and has the properties of water. The temperature influence on the plate deformations is not included in the considerations.

The test cases chosen for the comparison are based on references [5] and [6]. In the technical report [5] the authors presented results of an experimental and computational analysis performed to evaluate the capability of the fluid-structure interaction of various software on the example of a Missouri University Research Reactor (MURR) fuel element plate. Flat and curved plates were considered. Simulations of the experiments were performed at Missouri University with the use of Simcenter STAR-CCM+ coupled with Simulia ABAQUS software. Independently, researchers at Argonne performed simulations using the STAR-CCM+ built-in fluid-structure interaction modeling capabilities. Reference [6] aims at assessing the capabilities of STAR-CCM+ in modeling pressure differential induced deflections as well as providing an estimate of the deflection magnitude of LEU involute plates. The finite volume solver was used to solve the flow and finite element solver was used for the structure response calculations with two-way coupling between these two solvers.

Additionally, a discussion of results for two benchmark cases, a cantilever beam, and a cylindrical shell under bending loads is presented in the Appendix A.

\subsection{Involute-Plate Reactors}

Fuel elements of involute-plate reactors have an annular shape as depicted in Figure 1.1, which shows a top view, from left to right, of the HFIR, RHF and FRM II fuel elements, respectively. HFIR has two elements (inner and outer) while RHF and FRM II have only one. The fuel elements of these reactors are located at the center of a larger vessel that contains the reflector (heavy water for RHF and FRM II, beryllium for HFIR) as well as experimental and safety devices. The cylindrical volume located at the center of the annular fuel elements is often referred to as the central cavity. FRM II and RHF use this space for the control elements, which move vertically to control the reactivity during the cycle. HFIR uses this central cavity for isotope production. HFIR reactivity control is assured by an inner and outer shroud located near the outer edge of the outer element.
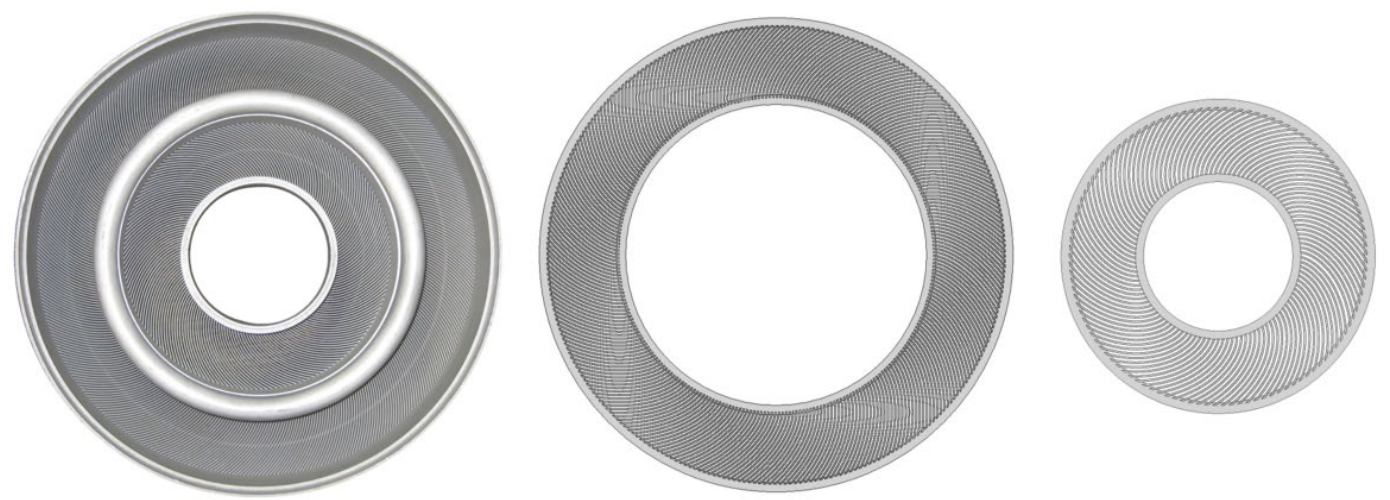

Figure 1.1. From left to right, top view of the HFIR, RHF, and FRM II fuel elements (close to true proportionality).

The involute shape allows for:

- the thickness of a coolant channel to be constant from the inner to the outer edge of the element,

- all channels to be identical (granted some local deviations due to imperfections in the manufacturing process), 
- all fuel plates to experience very similar irradiation conditions (granted some possible local azimuthal variations induced by the presence of safety or experimental components located at the vicinity of the fuel elements).

To provide a more detailed view of the involute fuel plates and coolant channels, Figure 1.2 shows a photo taken of an RHF mockup and Figure 1.3 a sketch of a close-up view. As presented in the figures, the fuel plates curved as involute are attached to two concentric plates (commonly referred to as side plates). Vertical grooves are machined in the side plates to allow insertion of the fuel plates that are then welded to the side plates at multiple, about 25 , locations along the vertical axis. The fuel plates are very thin (from $1.27 \mathrm{~mm}$ to $1.36 \mathrm{~mm}$ ) and have a sandwich-like structure. The fuel is made of HEU (93 wt. \%) mixed with aluminum. The fuel core is surrounded by cladding made of A6061. More design information on these fuel elements can be found in Table 1.1.

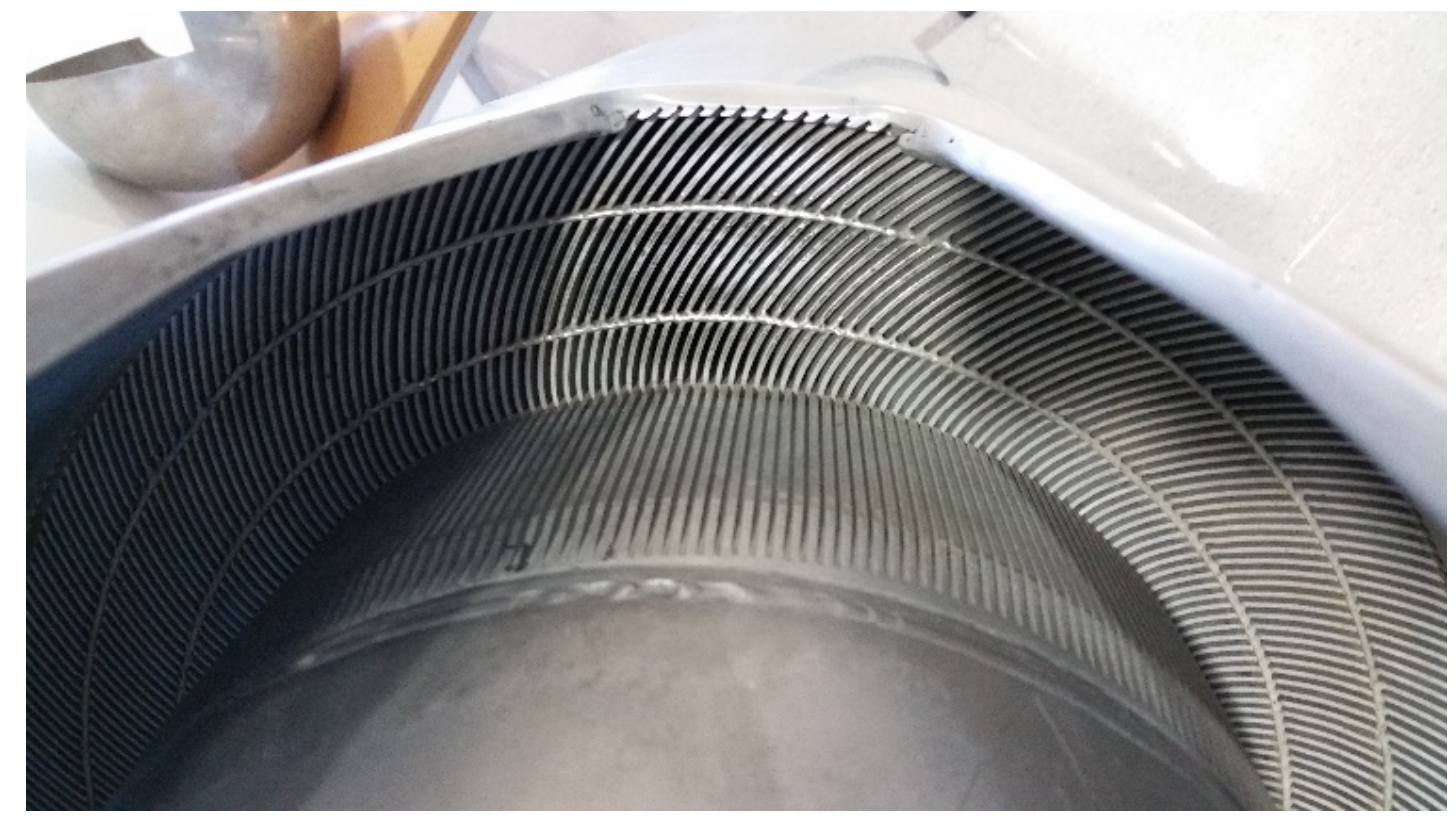

Figure 1.2. View of RHF fuel plates curved as involute and welded between the two annular side-plates (picture taken from a mockup and not a real element, finish is therefore not representative of a real element).

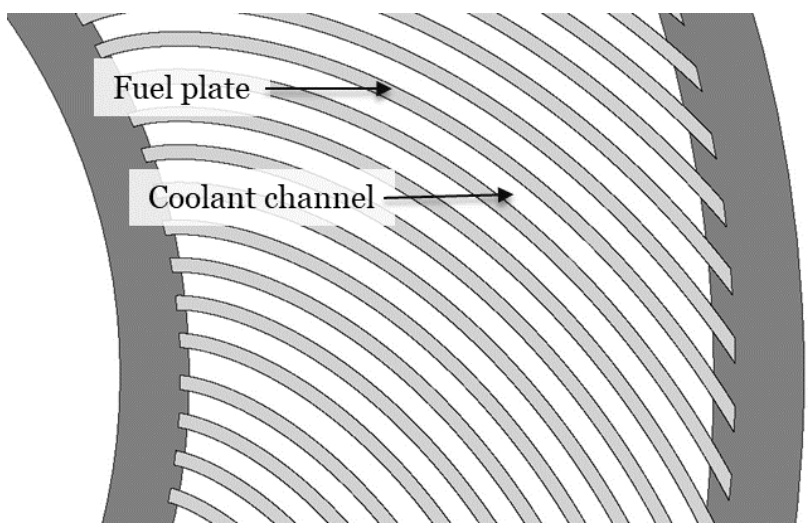

Figure 1.3. Sketch of the involute fuel plates installed in the side plates. Note that the shape of the plates guarantees a constant coolant channel thickness. 
Table 1.1. Key parameters of fuel elements in involute reactors.

\begin{tabular}{|l|c|c|c|}
\hline \multicolumn{1}{|c|}{ Parameters } & $\begin{array}{c}\text { HFIR } \\
{[7]}\end{array}$ & $\begin{array}{c}\text { RHF } \\
{[8]}\end{array}$ & $\begin{array}{c}\text { FRM II } \\
\text { [9] }\end{array}$ \\
\hline Fuel type & $\mathrm{U}_{3} \mathrm{O}_{8} / \mathrm{Al}$ & $\mathrm{UAlx} / \mathrm{Al}$ & $\mathrm{U}_{3} \mathrm{Si}_{2} / \mathrm{Al}$ \\
\hline Cladding material & $\mathrm{Al}-6061$ & $\mathrm{AlFeNi}$ & $\mathrm{AlFeNi}$ \\
\hline Number of elements & 2 & 1 & 1 \\
\hline Number of plates & $540(171+369)$ & 280 & 113 \\
\hline Plate thickness (mm) & 1.27 & 1.27 & 1.36 \\
\hline Plate length (cm) & 60.96 & 90.30 & 72.00 \\
\hline Channel width between side plates (cm) & $8.548 / 7.679$ & 7.594 & 6.940 \\
\hline Channel thickness (mm) & 1.27 & 1.80 & 2.20 \\
\hline Cladding thickness (mm) & 0.254 & 0.380 & 0.380 \\
\hline Fuel core thickness (mm) & $\begin{array}{c}\text { Varies along width; } \\
\text { max: } 0.693\end{array}$ & 0.51 & 0.60 \\
\hline Fuel core width (cm) & $7.798 / 7.087$ & 6.734 & 6.240 \\
\hline $\begin{array}{l}\text { Width of inner unfueled region (from outer radius } \\
\text { of inner side-plate to inner fuel radius, cm) }\end{array}$ & $0.234 / 0.218$ & 0.314 & 0.259 \\
\hline $\begin{array}{l}\text { Width of outer unfueled region (from outer fuel } \\
\text { radius to inner radius of outer side-plate, cm) }\end{array}$ & $0.516 / 0.374$ & 0.547 & 0.441 \\
\hline
\end{tabular}

Table 1.2 provides key thermal hydraulic parameters for the HEU fuel elements used in the involute reactors. RHF uses heavy water as coolant while FRM II and HFIR use light water. The coolant flows from top to bottom for all three reactors. The space between two adjacent fuel plates forms a coolant channel in which water passes at speeds up to $\approx 17 \mathrm{~m} / \mathrm{s}$, to evacuate the heat generated in the fuel plate by nuclear reactions. These reactors operate with coolant at relatively low pressure and temperature which leads to cladding temperatures on the order of $100{ }^{\circ} \mathrm{C}$ and, because of the high thermal conductivity of the cladding and fuel core, nominal (without uncertainties) fuel temperature does not exceed $150^{\circ} \mathrm{C}$.

Table 1.2. Key thermal-hydraulic parameters in involute reactors.

\begin{tabular}{|l|c|c|c|}
\hline \multicolumn{1}{|c|}{ Parameters } & $\begin{array}{c}\text { HFIR } \\
\text { [7] }\end{array}$ & $\begin{array}{c}\text { RHF } \\
\text { [8] }\end{array}$ & $\begin{array}{c}\text { FRM II } \\
\text { [9] }\end{array}$ \\
\hline Coolant type & Light water & Heavy water & Light water \\
\hline Average coolant velocity (m/s) & 15.5 & 17 & 15.9 \\
\hline $\begin{array}{l}\text { Nominal inlet / outlet bulk coolant temperature } \\
\text { (Celsius) }\end{array}$ & $49 / 69$ & $30 / 50$ & $38 / 59$ \\
\hline Nominal inlet / outlet pressure (Pa x 105) & $33.3 / 25.72$ & $14 / 4$ & $8.8 / 2.3$ \\
\hline
\end{tabular}

\subsection{Involute Working Group}

In the framework of its non-proliferation policies, the international community aims at eliminating the use of HEU $(235 \mathrm{U} / \mathrm{U} \geq 20 \mathrm{wt}$ \%) fuel in civilian facilities (such as research reactors) [9]. Many organizations worldwide are developing high density, LEU $(235 \mathrm{U} / \mathrm{U}<20 \mathrm{wt}$. \%) fuel to replace the HEU fuel. All three involute-reactor operators, ONRL, ILL, and TUM, are actively engaged in conversion to LEU activities.

Conversion to LEU implies changing the fuel and therefore changing its material properties, which influences the thermal and thermal-mechanical behavior of the elements. In many cases, it also implies making geometric modifications, such as changing plate span, channel thickness, and others, which may also affect the thermal-mechanical performance of the elements. 
To understand the effect of these changes, Argonne National Laboratory and the involute reactors formed an informal group working on the validation of numerical models and software for plate analysis. This so-called Involute Working Group (IWG) aims, among other things, to support the qualification of high-fidelity numerical tools for thermal-hydraulic safety calculations [10], [11], and thermal-mechanical analysis. Activities include benchmarking, code-to-code comparison, verification, and validation of the computational methods, as well as technical support.

As part of the IWG scope of work, the goals of the analysis presented here are:

- assess of STAR-CCM+ as a computational tool for FSI analysis of the reactor fuel plates,

- evaluate of the finite volume and finite element methods available in the software for modeling of fuel plates,

- perform fluid-structure interaction between the fuel plate and coolant,

- perform foundational work before commencing the LEU design mechanical analysis. 


\section{Computational Modeling}

Reactor fuel plates are flat or curved structures with the thickness being three orders of magnitude smaller than the other two dimensions and therefore, from the point of view of structural mechanics, fuel plates could be classified as shells [12]. Derivation of governing equations that would be applicable to such thin structures of various geometries is complicated and oftentimes leads to simplified formulations. Numerical methods, such as the finite element method, play an important role in solving these problems. Various finite element formulations were developed, with a better or worse outcome. Some 3D solid hexahedral finite elements such as displacement-based with full integration, show spurious stiffening, called a membrane and bending (shear) locking, which results in greatly underestimated deflections of the structure, especially in bending-dominated problems. Various countermeasures were proposed and introduced to alleviate this issue e.g., reduced integration, enhanced strain field, or mixed displacement-stress formulation, among others [13]. Solid finite element formulations in FSI problems allow for modeling of the plate and channel geometry in three-dimensional space, which in turn makes it possible to represent the coolant flow around the plates.

In STAR-CCM+, the Finite Element Solid Stress solver for modeling solid bodies has been available only since the 2015 version v.10.04. Up until then, Finite Volume Method was the only solid stress solver available. Over the last few years, both approaches were being developed and widely used by researchers and engineers. Recently it was announced that by the end of 2021 Finite Volume Stress solver will no longer be available in the code and only the Finite Element Solid Stress solver will be available. This section presents a short description and comparison of the two computational methods.

\subsection{Finite Volume vs. Finite Element Methods for Modeling Thin Structures in Bending}

Finite volume cells carry the values of field variables, like displacements or stresses, in cell centroids which means that the fields are constant within a cell. Typically, a thin structure under bending loads requires more finite volume cells than finite elements, in-plane and across the thickness, to obtain a mesh-independent solution. According to the STAR-CCM+ documentation [4] the finite volume mesh should have at least 2 to 3 cells to calculate a gradient through the thickness. Also, it is recommended to have cells with an aspect ratio close to one to get a good convergence of the result. In general, it is not recommended to use the finite volume approach when the ratio of the distance between supports to the thickness becomes greater than twenty. The documentation includes a statement saying that with a sufficient cell density the bending displacements and stresses may be resolved.

When a plate is meshed coarsely in-plane with the use of finite volume cells, the displacements are greatly underestimated, because the interpolating functions are constant within a cell. The interpolation functions are not suitable to accurately represent the strain distribution, and therefore the solution converges very slowly as the cell size is decreased. On the other hand, finite volume method overestimates the deflections if a coarse mesh is used across the thickness of the plate. The equations are solved at cell centers, which are half-a-cell-width away from the plate boundaries, without any numerical methods to account for that distance. Computationally, the plate is thinner by a cell thickness, which leads to an increase in deflection magnitude. Using finite volume stress solver with a coarse mesh is reasonable only for cases of very bulky geometries with low stresses, or when a solid is discretized with an extremely fine mesh.

Involute Working Group - FSI Analysis of Fuel Plates Using Finite Volume and Finite Element Methods 
Using the finite element solver instead of the finite volume solver leads to significant savings in computational resources and time. The finite element formulations available in STAR-CCM+ have linear and quadratic interpolation of displacements within an element, which results in a reduction of the required computational cells. The linear finite elements solve for displacements at the corner nodes and the quadratic finite elements at the corner nodes and additional mid-side nodes. This means that the field variables, as well as the geometry, boundary constraints, and loads, can be more accurately represented than when using finite volume cells. A sketch of a finite volume cell, an 8-node finite element with linear shape functions and a 20-node finite element with quadratic shape functions are presented in Figure 2.1.
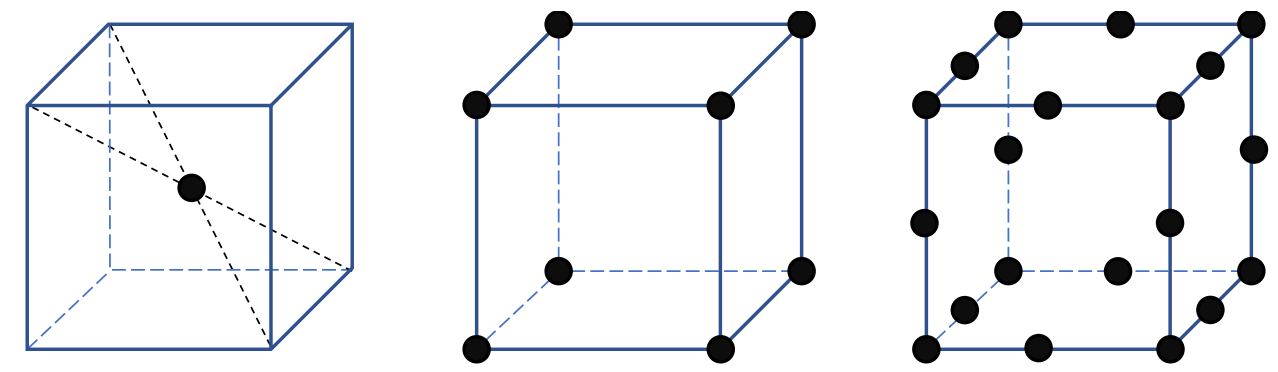

Figure 2.1. Finite volume cell with a node in the cell centroid (left), an 8-node finite element Hex8 (center) and a 20-node finite element Hex20 (right).

Two classical benchmark cases were selected to show the differences in the solution when these solvers are used. A cantilever beam under bending load and a so-called Scordelis-Lo roof problem are presented in Appendix A. Both cases share similarities with the problems that IWG focuses on. Both are structures subjected to loads that cause bending, the same as the pressure differential acting on a fuel plate. The cantilever beam has a parabolic traction load applied to the free tip, which tests the ability of the formulation to represent complex load distributions, which occur in the reactors. The Scordelis-Lo roof is a thin curved structure that deforms under its own weight. The shape of the roof resembles the shape of the cylindrical fuel plates and therefore is helpful in testing mesh sensitivity.

\subsection{Fluid-Structure Interaction Analysis}

Fluid-structure interaction is a thermo-mechanical interaction between a fluid and a solid structure. The interaction can be of two types: one-way and two-way interaction. If the pressure differential from the moving fluid causes small deformations of the plate, the fluid's behavior does not change significantly. In this case, only the influence of the fluid on the structure can be accounted for in the model. This is a so-called one-way interaction or one-way coupling. If the deformation of the plate causes a significant change in the channel thicknesses and therefore influences the fluid flow, twoway interaction modeling should be used.

It will be shown in the following sections of the report, that for some combinations of flow velocity magnitude and plate thickness, using two-way coupling is essential. The deformation of the plate into a channel requires a modification of the fluid grid, via so-called morphing. When the structure moves with respect to the fluid, the fluid mesh is distorted to conform to the mesh on the surface of the structure. In some cases, when two structures move nearby, mesh morpher leads to a poor-quality mesh and the simulation diverges. 


\subsection{Reference Models}

The models considered in the current study represent the volume between two side-plates occupied by a single fuel plate and the neighboring coolant channels, as well as additional sections upstream and downstream from the plate leading and trailing edges, respectively. These sections are representing the plena in the reactor.

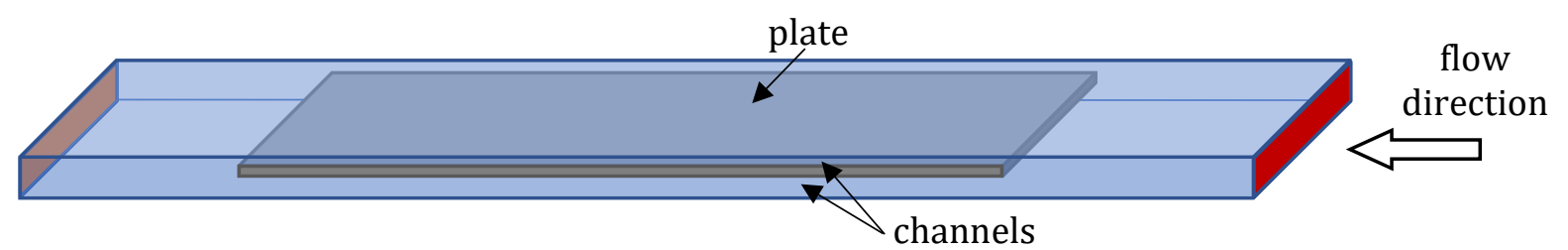

Figure 2.2. Sketch of an example CFD model of a flat plate between two channels and additional plenum upstream and downstream of the plate.

Figure 2.2 shows the geometry of a generic CFD model. The surface marked in red is a velocity inlet boundary condition with a constant velocity magnitude. The surface marked in orange is a pressure outlet boundary condition with atmospheric gauge pressure. The remaining surfaces are defined as a no-slip smooth wall boundary condition. In this figure, the outside surfaces of the computational domain have partial transparency that allows for displaying the plate positioned between the channels. The plate is assigned a Solid Region type, and the channels a Fluid Region type. A Mapped Contact Interface is defined between the regions, which is an indirect interface type between fluidsolid and solid-solid boundaries that allows for a non-conformal mesh.

The length of the upstream section allows for development of the flow and the downstream section ensures that there is no influence of the outlet boundary condition on the flow in the channels and therefore the deflections of the plate. The fuel plate and channels have an ideal shape with walls parallel to the flow direction. The channels have a different thickness to introduce a pressure differential acting on the plate. No other imperfections of the geometry or boundary conditions were accounted for, as the analysis focuses on the comparison of the computational methods used for modeling solids and not representing the actual conditions in the reactors.

Directed Mesher is chosen to create the mesh because it gives the most control over the grid cell size out of the mesh generation algorithms available in the software. A mesh created on a source surface is swept across the volume to the target surface with a specified number of divisions that can be uniform or nonuniform. An example of discretization is presented in Figure 2.3. The resulting mesh is conformal, which means that the vertices of finite elements and finite volumes, in the solid and fluid respectively, overlap. A conformal mesh is always preferred over a non-conformal mesh because it avoids interpolation at the interface between parts, which in turn reduces computational time and ensures higher accuracy of the solution. In the case of a conformal mesh, the change in the number of elements along the width and length of the plate changes the discretization of the fluid, which may lead to a change in the pressure differential load acting on the plate. This change is shown in an example case of a flat plate in Section 3.1. 


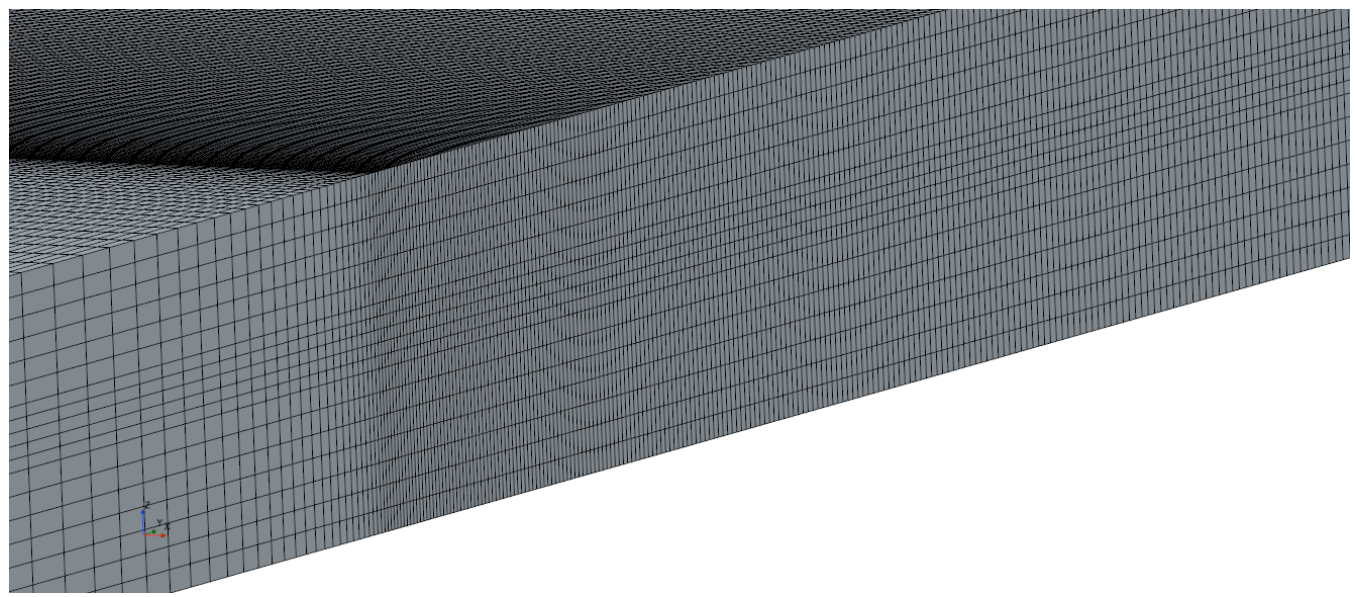

Figure 2.3. An example discretization of the computational domain.

It is assumed that the fuel plate is made of pure aluminum A-6061. Previous studies showed that neglecting the composite structure of the plate including the fuel core and the cladding does not significantly influence plate deflections [14]. The mechanical properties of aluminum are: density equal $2702 \mathrm{~kg} / \mathrm{m}^{3}$, elastic modulus equal $68.0 \mathrm{GPa}$, and Poisson's ratio equal 0.33. An isotropic linear elastic material model was chosen to represent the aluminum in the models. Material properties of water are: density $997.561 \mathrm{~kg} / \mathrm{m}^{3}$, dynamic viscosity $8.8871 \times 10^{-4} \mathrm{~Pa}$.

\subsubsection{Flat Fuel Plate}

The computational model presented in [5] has a shape of a cuboid with a thin plate inside. The analysis was performed for an ideal flat plate situated between two channels of different thickness. The geometry of the model is shown in Figure 2.4 and the dimensions are presented in Table 2.1.. The flow rate varied from $1.04 \mathrm{~kg} / \mathrm{s}$ to $4.34 \mathrm{~kg} / \mathrm{s}$, which corresponds to an average channel velocity of $2.07 \mathrm{~m} / \mathrm{s}$ and $8.63 \mathrm{~m} / \mathrm{s}$, respectively. Two-way coupling between the fluid and solid was deemed essential to obtain realistic results, because under these flow conditions the plate experiences substantial deflections as compared to the channel thickness. Two computational models were built independently, a fully coupled model in STAR-CCM+ and a co-simulation of STAR-CCM+ flow solver and ABAQUS structural solver. In the fully coupled model, the Finite Volume solver was used to model both the fluid and solid, which at the time was the only way to perform an FSI analysis fully within STAR-CCM+ code. In the co-simulation, finite volume solver was used to solve the flow equations, and finite element method to solve the solid stress equations.

Table 2.1. Dimensions of the flat fuel plate model.

\begin{tabular}{|l|c|}
\hline Wide channel thickness, $\mathrm{h}_{1}[\mathrm{~mm}]$ & 2.54 \\
\hline Narrow channel thickness, $\mathrm{h}_{2}[\mathrm{~mm}]$ & 2.03 \\
\hline Plate thickness, $\mathrm{h}_{\text {plate }}[\mathrm{mm}]$ & 1.02 \\
\hline Downstream section length, $\mathrm{L}_{\text {out }}[\mathrm{mm}]$ & 76.2 \\
\hline Plate length, $\mathrm{L}_{\mathrm{p}}[\mathrm{mm}]$ & 647.7 \\
\hline Upstream section length, $\mathrm{L}_{\text {in }}[\mathrm{mm}]$ & 190.5 \\
\hline Plate width, $\mathrm{b}[\mathrm{mm}]$ & 110.3 \\
\hline Ratio of plate width to thickness, $\mathrm{b} / \mathrm{h}_{\text {plate }}$ & 108 \\
\hline
\end{tabular}




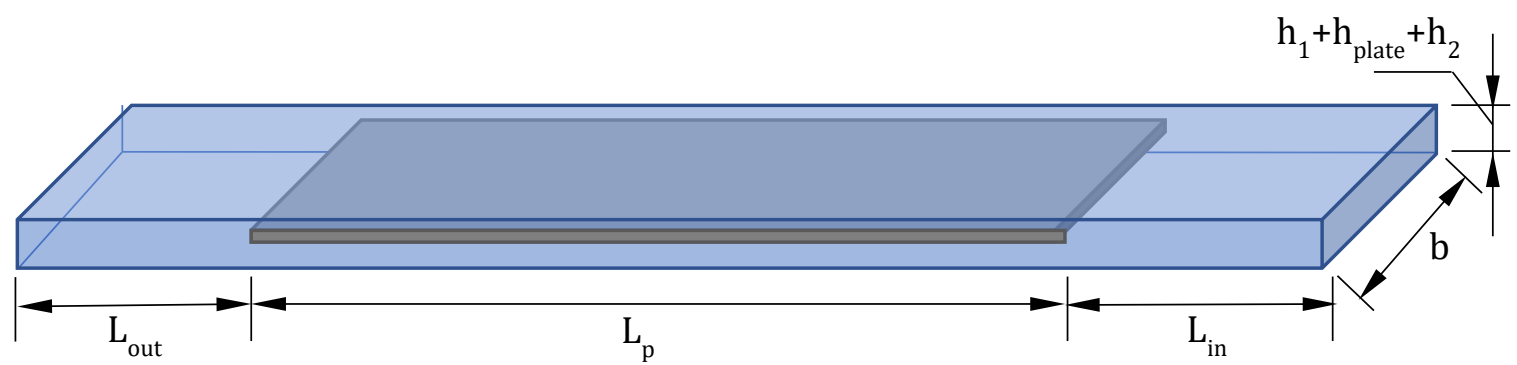

Figure 2.4. Sketch and dimensions of the flat fuel plate model.

According to the report [5], the mesh sensitivity study on the fully coupled model showed that a mesh with the aspect ratio of 1,4 , and 1 in $x, y$, and $\mathrm{z}$ direction with a cell size of $0.2 \mathrm{~mm}$ gives a mesh independent solution. The analysis showed that the results are more sensitive to the mesh aspect ratio in the width direction than in the main flow direction. Deflections of the plates for various fluid loads were extracted along an axial path crossing the point of maximum deflection. An example comparison between the two models with an average channel velocity of $8 \mathrm{~m} / \mathrm{s}$ is shown in Figure 2.5. Both approaches give a similar shape of the deflection curve and differ in the deflection magnitudes by less than $0.1 \mathrm{~mm}$, with finite volume giving the higher estimate of displacement.

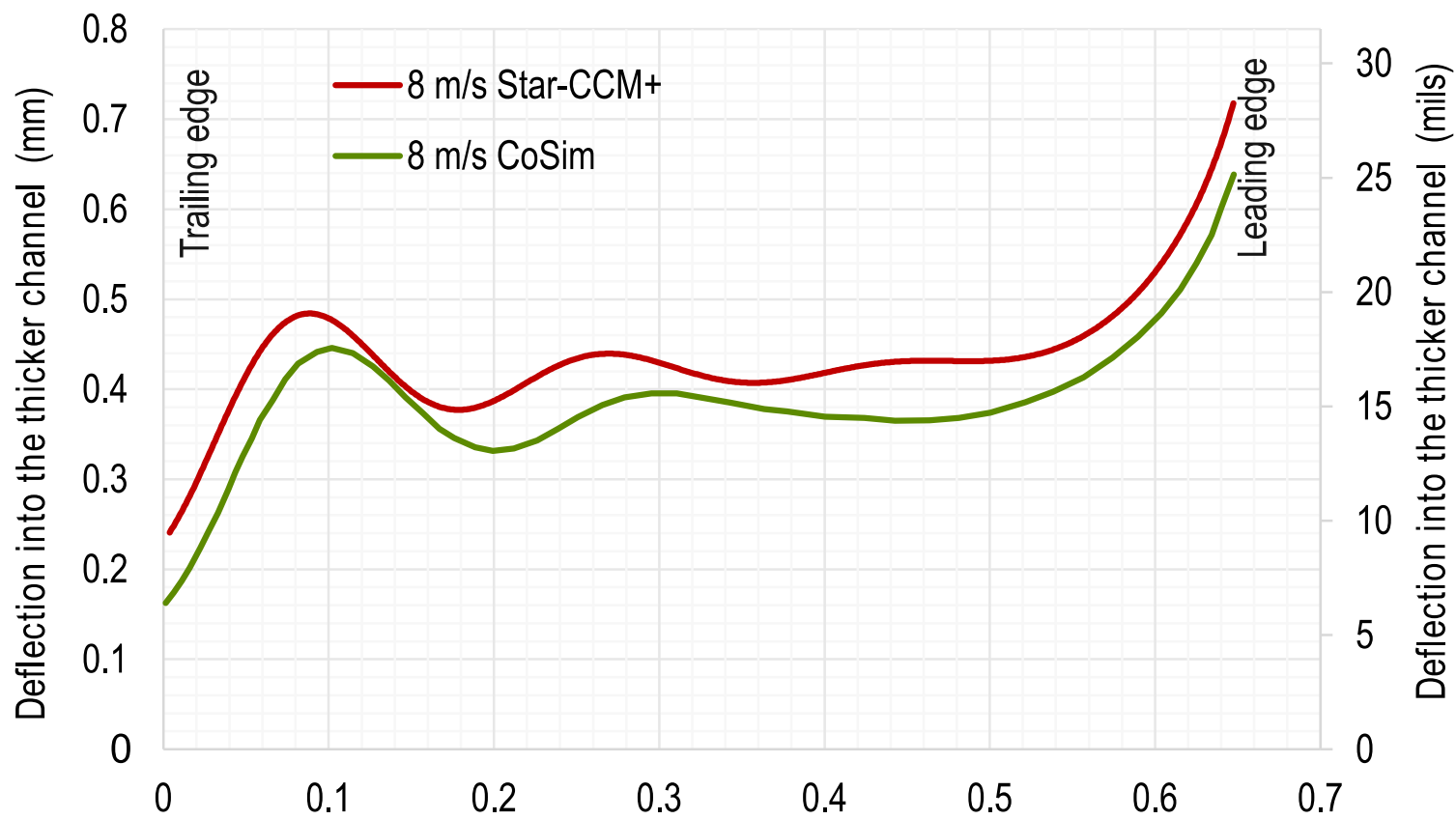

Distance from Trailing Edge $(\mathrm{m})$

Figure 2.5. Deflection along the symmetry line of the $1.06 \mathrm{~mm}$ plate and $8 \mathrm{~m} / \mathrm{s}$ average channel flow velocity obtained with the use of STAR-CCM+ finite volume solver and cosimulation approach with ABAQUS [5].

\subsubsection{Cylindrical Plate}

Technical report [5] covers an analysis of a flat fuel plate presented in Section 2.3.1, and also a cylindrically curved geometry that mimics the shape of the University of Missouri Research Reactor (MURR®) fuel plates. The University of Missouri Research Reactor has eight fuel elements, stacked 
within an annulus, covering approximately a $45^{\circ}$ section each. The outer plate with the largest span was chosen for analysis. The geometry of the model is presented in Figure 2.6.

Two plate thickness values were considered in the present study: $0.66 \mathrm{~mm}$ and $0.40 \mathrm{~mm}$. The dimensions of the plates are given in Table 2.2, where the models with different plate thicknesses are called Case 1 and Case 2, respectively.

The tolerances of the channel thickness may lead to flow disparities which cause pressure differential inducing plate deflections. Two cases were considered: when the channel on the convex side of the plate is thicker, and the one on the concave side is thinner (concave loading), or vice versa (convex loading). A parametric study was performed and presented in [5] using both loading cases, varying plate thickness from $0.4 \mathrm{~mm}$ to $1.27 \mathrm{~mm}$, and flow velocity from $3 \mathrm{~m} / \mathrm{s}$ to $40 \mathrm{~m} / \mathrm{s}$. The results obtained with finite volume solver used for the fluid and the plate were compared against those obtained from co-simulations with ABAQUS, as well as, after Star-CCM+ v.10.06 was released, with a model in which finite element solver was used to model solid and finite volume solver to model fluid.

(a)

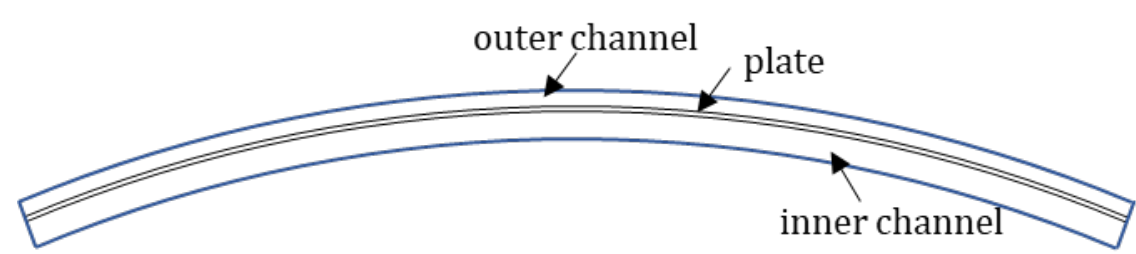

(b)

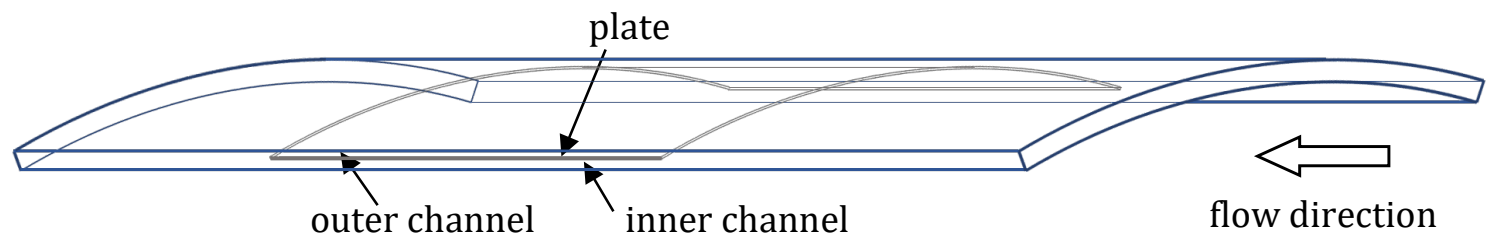

Figure 2.6. Geometry of the CFD model with a cylindrical fuel plate, (a) top view, (b) perspective view.

Table 2.2 Dimensions of the cylindrical plate model.

\begin{tabular}{|c|c|c|c|}
\hline & Case 1 & Case 2 & $\begin{array}{c}\text { Case } 2 \\
\text { "as-built" }\end{array}$ \\
\hline $\begin{array}{l}\text { Wide channel thickness, } \mathrm{h}_{1}[\mathrm{~mm}] \\
\text { (concave side) }\end{array}$ & 2.54 & 2.92 & 3.30 \\
\hline $\begin{array}{l}\text { Narrow channel thickness, } \mathrm{h}_{2}[\mathrm{~mm}] \\
\text { (convex side) }\end{array}$ & 2.03 & 1.63 & 1.98 \\
\hline Plate thickness, $\mathrm{h}_{\text {plate }}[\mathrm{mm}]$ & 0.66 & \multicolumn{2}{|c|}{0.40} \\
\hline Upstream section length, $\mathrm{L}_{\text {in }}[\mathrm{mm}]$ & \multicolumn{3}{|c|}{190.5} \\
\hline Plate length, $\mathrm{L}_{\mathrm{p}}[\mathrm{mm}]$ & \multicolumn{3}{|c|}{647.7} \\
\hline Downstream section length, $\mathrm{L}_{\text {out }}[\mathrm{mm}]$ & \multicolumn{3}{|c|}{76.2} \\
\hline Arc length, $\mathrm{L}_{\mathrm{arc}}[\mathrm{mm}]$ & 110.0 & 111.45 & 111.46 \\
\hline Arc angle [deg] & \multicolumn{3}{|c|}{45} \\
\hline Inner radius, $\mathrm{r}_{\mathrm{in}}[\mathrm{mm}]$ & \multicolumn{2}{|c|}{141.2} & 141.5 \\
\hline
\end{tabular}


The mesh sensitivity study of the fully finite volume model performed by ANL [5] showed that only a very fine mesh leads to plate deflections comparable with those obtained from ABAQUS. When a high aspect ratio of the cells was used, the results at higher velocities diverged from the co-simulation results, which led to a model with a nonuniform mesh with 800 by 500 (or even 800 ) by 6 cells along the length, width, and thickness of the plate, respectively, and the smallest cell size at the center of the leading edge of the plate.

A set of simulations was performed for a modified model, referred to as "as-built", in which the channel thickness was modified, as compared to Case 2. The modified dimensions of the computational model are collected in Table 2.2 in the 'Case 2 "as-built"' column. Fluid-structure interaction simulations for this case were performed with the use of a finite element solver, alongside the Finite Volume solver. Using the finite element solver reduced the number of computational cells by an order of magnitude. At the same time, the maximum deflections were $20 \%$ smaller. Figure 2.7 shows a comparison of the maximum deflection magnitude of the $0.4 \mathrm{~mm}$-thick plate from STAR$\mathrm{CCM}+$ simulations using finite element and finite volume solvers, as well as co-simulations between STAR-CCM+ and ABAQUS. The STAR-CCM+ finite volume solid stress solver gives the largest maximum displacements, whereas the finite element stress solver results are the lowest, with the biggest difference for the highest considered coolant velocity. The maximum magnitude of displacement are respectively $2.29 \mathrm{mil}(0.058 \mathrm{~mm}), 2.03 \mathrm{mil}(0.052 \mathrm{~mm}), 1.85 \mathrm{mil}(0.047 \mathrm{~mm})$.

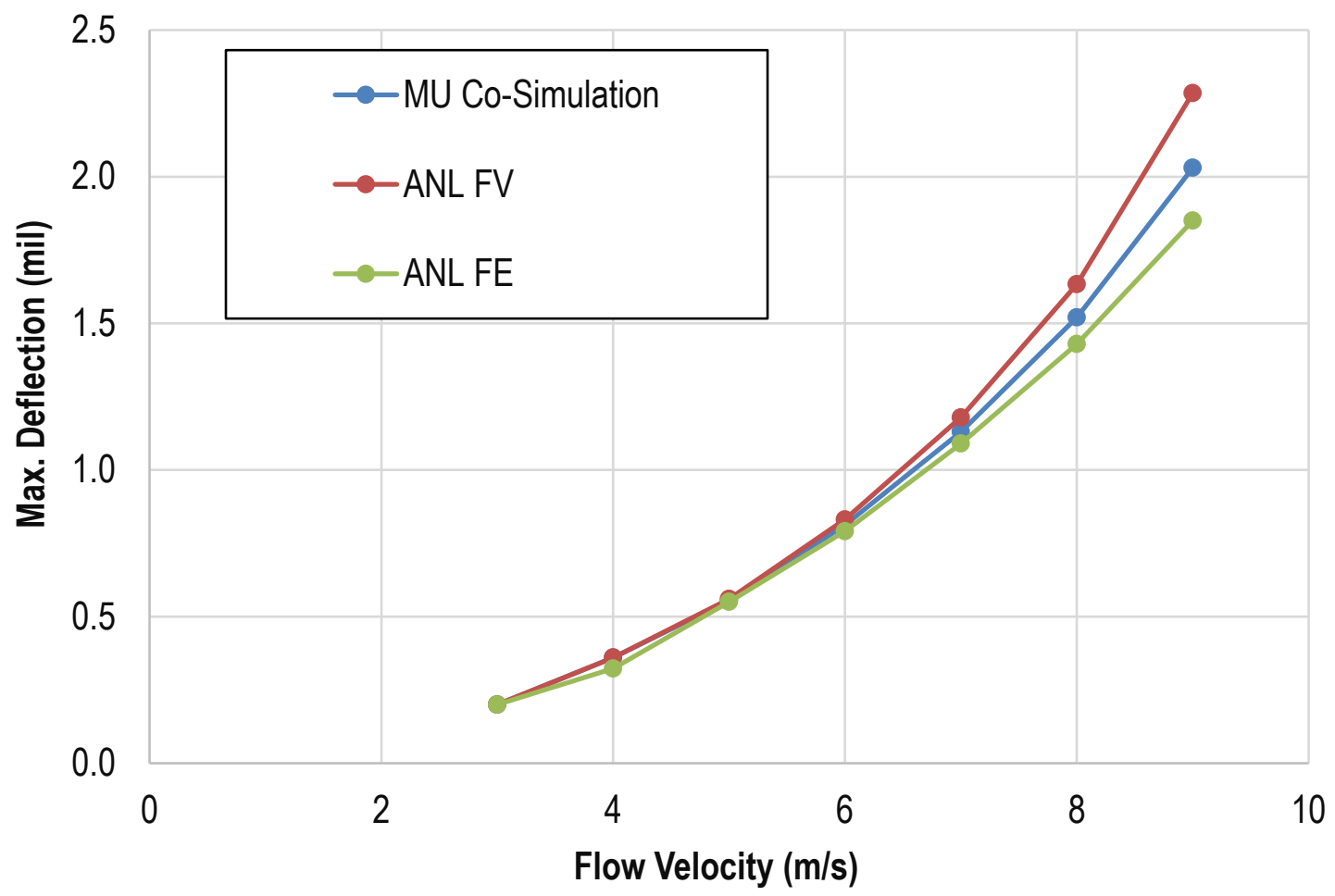

Figure 2.7. Deflection of the tip of the $0.4 \mathrm{~mm}$-thick plate computed with the use of the finite volume and finite element solid stress solver in STAR-CCM+, and co-simulation technique between STAR-CCM+ and ABAQUS [5].

\subsubsection{Involute Plate}

Circle-involute fuel plates are the main topic of interest for IWG. A previous study by Sitek et al. [4] focused on modeling the mechanical response of a single plate to thermal and pressure loads, without 
a full fluid-structure interaction analysis. Bojanowski et al. in [15] analyzed deflections of an involute plate due to hydrodynamic loads with the main goal of testing the influence of turbulence models on the flow distribution, pressure drop, and resulting deflections of the plate.

Figure 2.8 shows the geometry of the computational model used in [15]. The model is built similarly to the models presented in Sections 2.3.1 and 2.3.2 with the difference that on the sides of the upstream and downstream sections, cyclic boundary conditions are defined to allow for proper representation of the model as a part of radially repeatable geometry. The dimensions of the model are collected in Table 2.3.. Two cases are considered: a plate with a comb on the leading edge, and without it. A comb locally restricts the displacements of a fuel plate, with the goal of reducing the deflections. In the model, it is represented with a fixed displacement boundary condition on a section of the leading edge that represents the width of the comb.

Finite element solid stress solver is used to solve for the structural response of the fuel plate. Hexahedral finite elements with linear shape functions Hex8 were used to build the mesh for the solid part. The mesh has 19, 7, and 17 computational cells across the thickness of the thick channel, plate, and the thin channel, respectively, 300 elements in the axial direction, and 70 along the involute arc, totaling $\sim 1.3$ million computational cells.

The finite volume solver is used for flow calculations with various turbulence models: realizable k- $\varepsilon$, SST Menter k- $\omega$ with quadratic terms, and Reynolds Stress with elliptic blending. The biggest deflection of $0.022 \mathrm{~mm}$ is computed with the $\mathrm{k}-\omega$ model, the $\mathrm{k}-\varepsilon$ model gives $0.021 \mathrm{~mm}$, and the Reynolds Stress model: $0.017 \mathrm{~mm}$. Despite the differences between the solutions, the maximum estimated deflection of the plate constitutes only about $1 \%$ of the channel thickness. 


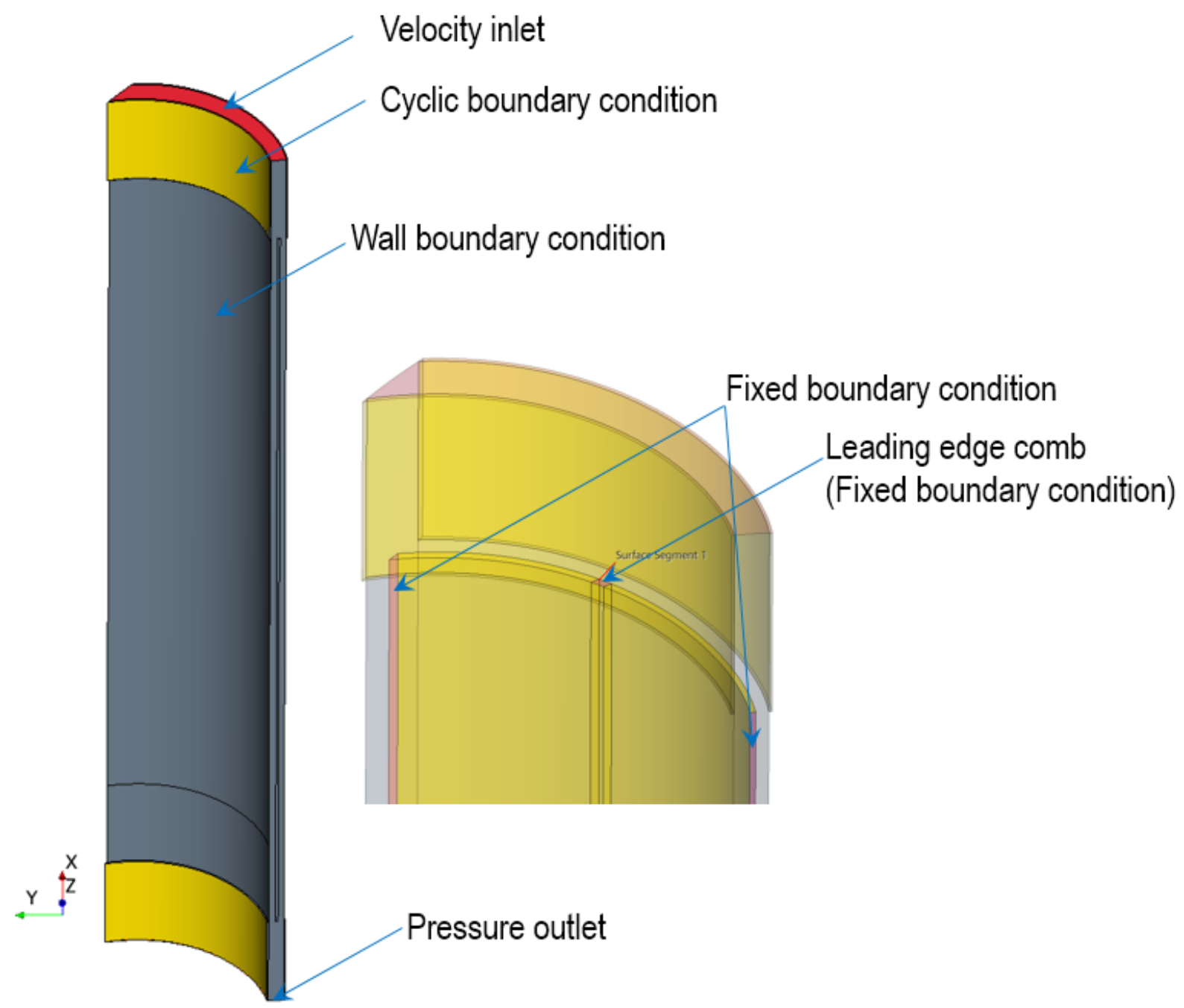

Figure 2.8. Geometry of the involute plate model used in a previous study [15].

Table 2.3. Dimensions of the involute plate model.

\begin{tabular}{|l|r|}
\hline Wide channel thickness, $\mathrm{h}_{1}[\mathrm{~mm}]$ & 2.85 \\
\hline Narrow channel thickness, $\mathrm{h}_{2}[\mathrm{~mm}]$ & 2.35 \\
\hline Plate thickness, $\mathrm{h}_{\text {plate }}[\mathrm{mm}]$ & 1.05 \\
\hline Downstream section length, $\mathrm{L}_{\text {out }}[\mathrm{mm}]$ & $\sim 100.0$ \\
\hline Plate length, $\mathrm{L}_{\mathrm{p}}[\mathrm{mm}]$ & 870.0 \\
\hline Upstream section length, $\mathrm{L}_{\text {in }}[\mathrm{mm}]$ & $\sim 100.0$ \\
\hline Arc length, $\mathrm{L}_{\text {arc }}[\mathrm{mm}]$ & $\sim 75.0$ \\
\hline
\end{tabular}


(a)

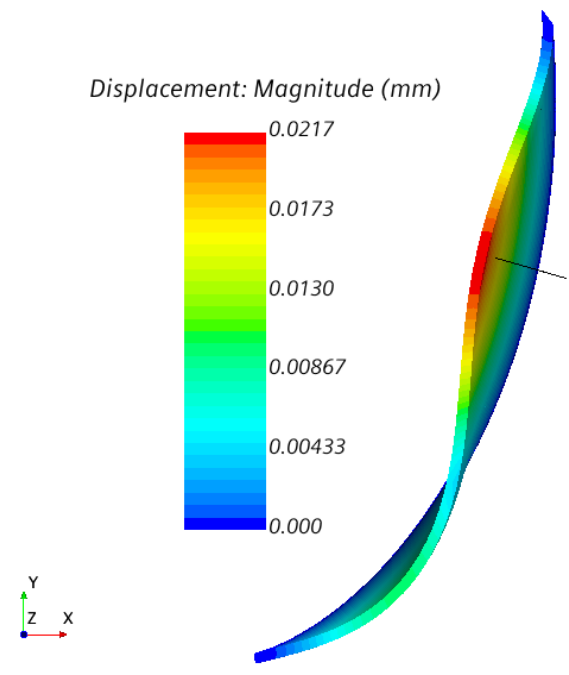

(b)

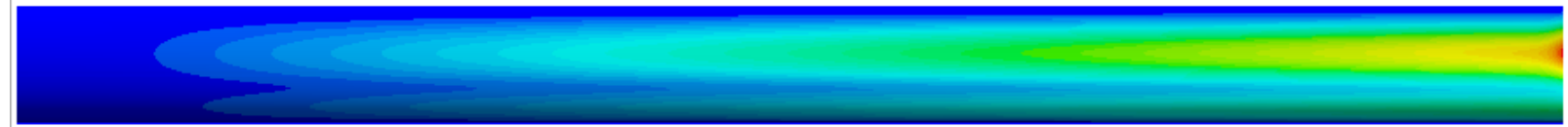

Figure 2.9. Displacements in the involute plate model (a) view of the leading edge, (b) view of the convex surface of the plate [15]. 


\section{Comparison of Fuel Plate Deflections Modeled with Different Solvers}

Various solvers are used to model the fuel plates: Finite Volume Solid Stress and Finite Element Solid Stress available in STAR-CCM+, as well as finite element formulations for modeling solids and shells provided by LS-DYNA. In a previous study [5], the cylindrical plate was also modeled with the use of a co-simulation capability that couples STAR-CCM+ with ABAQUS. These results are added to the report. The code-to-code comparison along with a mesh sensitivity analysis makes it possible to evaluate the quality of the solution. Section 3.1 of the report covers a flat plate model analysis, Section 3.2 presents an analysis of a cylindrical plate, and Section 3.3 presents involute plate modeling.

\subsection{Flat Fuel Plate}

The geometry of the model was recreated according to the description presented in Section 2.3.1 and a mesh sensitivity study was performed for the finite volume and finite element solvers. For simplicity, it was decided that the size mesh is uniform. This assumption facilitates the development of a corresponding model in LS-DYNA, which will be described in the following paragraphs. The mesh sensitivity study was performed for a case with an average coolant velocity in the channels of 3.36 $\mathrm{m} / \mathrm{s}$ (at the inlet boundary velocity is set to $2.83 \mathrm{~m} / \mathrm{s}$ ). Three grid densities were used with a uniform distribution: coarse mesh, which has 6 by 100 by 200 finite volumes (or finite elements) across thickness of the plate, along its width and length, respectively; medium mesh with 6 by 250 by 500 finite volumes/elements; and fine mesh with 6 by 500 by 800 volumes (or finite elements).

The mesh is conformal, created with the use of Directed Mesher, which means that the change in the number of elements along the width and length of the plate changes the discretization of the fluid, which in turn may lead to a change in the pressure load acting on the plate. Figure 3.1 presents a comparison of pressure differential distribution along the centerline of the plate for three discretizations. The major difference can be noticed in the vicinity of the leading edge of the plate, which has the biggest influence on the plate deflections. Despite the differences in pressure differential due to the mesh density, this test makes it possible to evaluate the finite volume and finite element solvers by comparison of solutions obtained for each of the meshes separately.

Two-way coupling and one-way coupling between the plate and fluid were modeled in STAR-CCM+. One-way coupling, in which the pressure differential from the moving fluid causes deformation of the plate, but the deformation is not used in the fluid solution to update the boundaries, can be used only when the deformation of the plate is negligible. If the deformation of the plate causes a change in the channel thicknesses and as a result a significant increase in the pressure differential, two-way coupling should be used.

A one-way coupling model was also developed in LS-DYNA to extend the analysis by a code-to-code comparison. Two types of finite element discretization was used: solid and shell finite elements [16]. The geometry of the plate was meshed out in LS-DYNA with solid finite elements that are intended for elements with poor aspect ratio (ELFORM=-2). The discretization density and distribution is the same as in the STAR-CCM+ model. The shell finite element formulation used (ELFORM=2), is based on Belytschko-Tsay formulation with 12 Gauss integration points across the thickness. The hydrodynamic pressure field was exported from a corresponding STAR-CCM+ model as a table and included in the LS-DYNA input file as a pressure load on the surfaces of the fuel plate. 
(a)
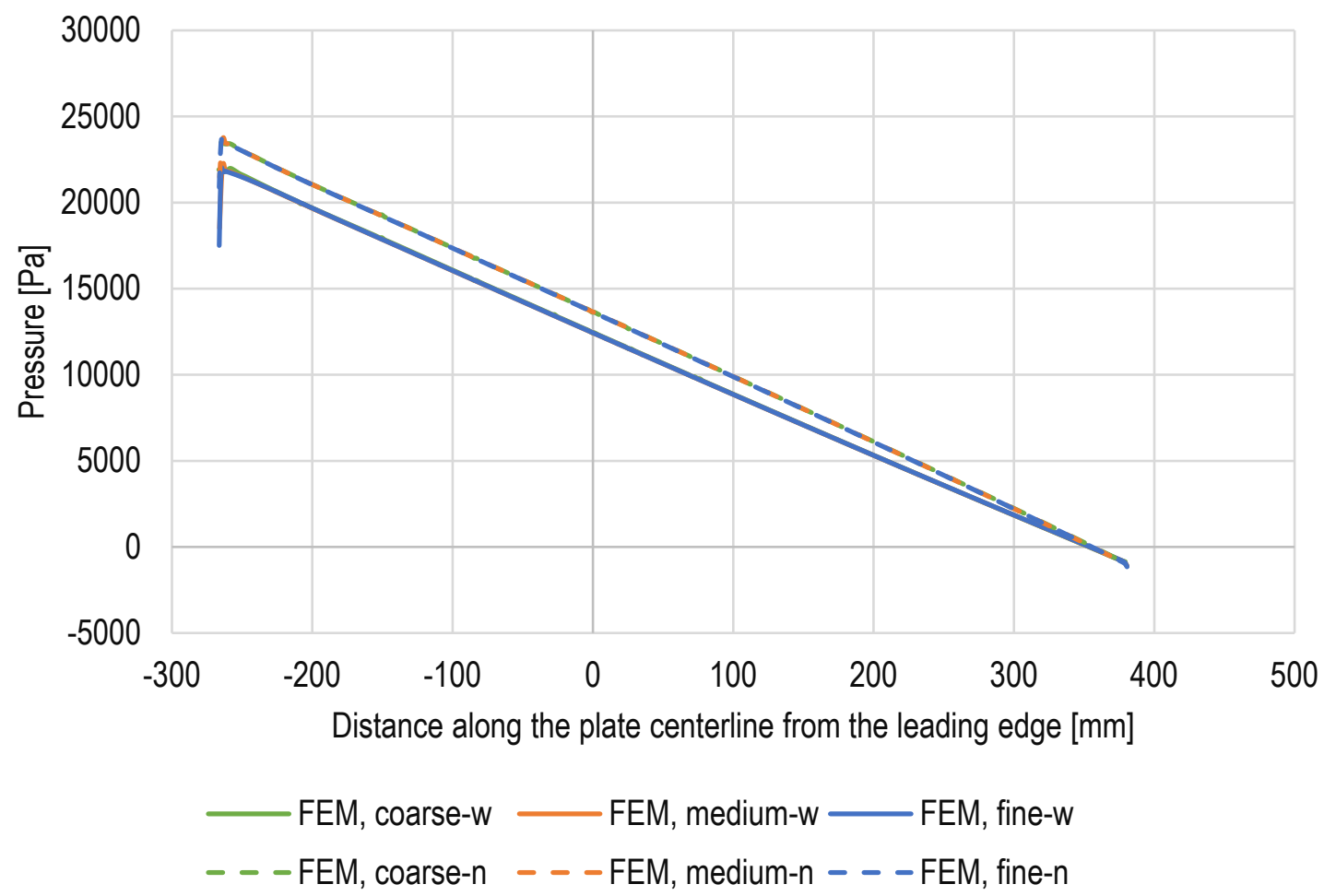

(b)

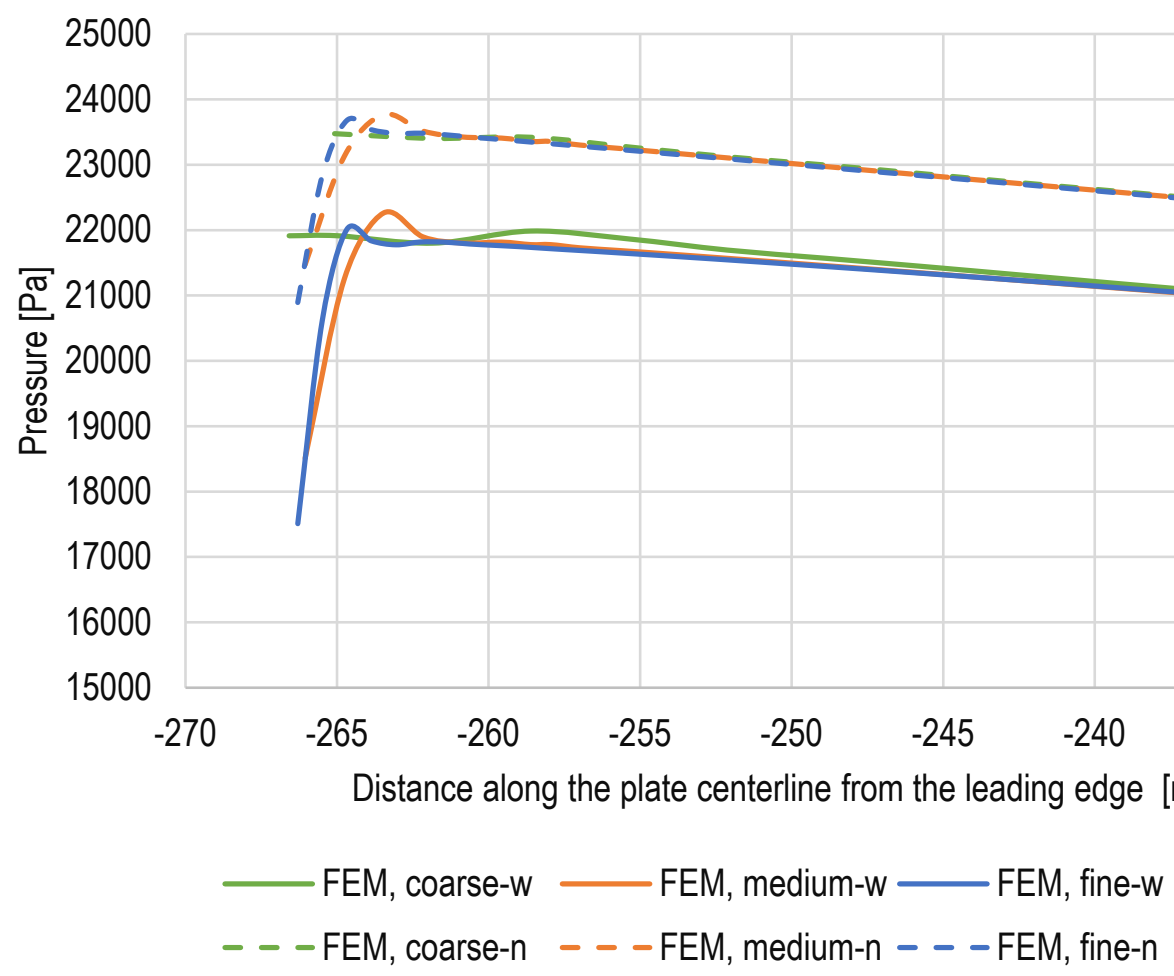

Figure 3.1. Pressure differential on the centerline of a flat fuel plate for varying Hex8 finite element mesh density, (a) along the full length of the plate, (b) close-up view of the leading edge. ( $w$ - wide channel side, $n$ - the narrow channel side). 
Table 3.1. Maximum deflection of a flat plate [mm].

\begin{tabular}{|c|c|c|c|c|c|c|c|}
\hline \multirow[b]{2}{*}{$\begin{array}{c}\text { Mesh } \\
\text { type }\end{array}$} & \multirow{2}{*}{$\begin{array}{l}\text { Number of } \\
\text { cells in } \\
\text { thickness } \\
(t), \text { width } \\
(w) \text {, and } \\
\text { length (l) } \\
\text { direction, } \\
t \times w \times 1\end{array}$} & \multicolumn{4}{|c|}{ STAR-CCM+ } & \multicolumn{2}{|c|}{ LS-DYNA } \\
\hline & & $\begin{array}{c}\text { Two-way } \\
\text { coupling, } \\
\text { FVM }\end{array}$ & $\begin{array}{c}\text { Two-way } \\
\text { coupling, } \\
\text { FEM }\end{array}$ & $\begin{array}{c}\text { One-way } \\
\text { coupling, } \\
\text { FVM }\end{array}$ & $\begin{array}{c}\text { One-way } \\
\text { coupling, } \\
\text { FEM }\end{array}$ & $\begin{array}{l}\text { One-way } \\
\text { coupling, } \\
\text { solid FEM }\end{array}$ & $\begin{array}{l}\text { One-way } \\
\text { coupling, } \\
\text { shell FEM }\end{array}$ \\
\hline Coarse & $6 \times 100 \times 200$ & 0.0387 & 0.0936 & 0.0364 & 0.0839 & 0.0827 & 0.0846 \\
\hline Medium & $6 \times 250 \times 500$ & 0.0759 & 0.1040 & 0.0686 & 0.0841 & 0.0882 & 0.0879 \\
\hline Fine & $6 \times 500 \times 800$ & 0.1065 & 0.1047 & 0.0885 & 0.0895 & - & - \\
\hline $\begin{array}{l}\text { Extra } \\
\text { fine }\end{array}$ & $6 \times 800 \times 1600$ & 0.1133 & - & - & - & - & - \\
\hline
\end{tabular}

Table 3.1 presents the values of maximum plate deflection for the considered cases. As shown in Figure 3.1, there are differences in loading due to the mesh density, which influences the deflections. Nevertheless, a comparison can be made between the different solvers. Figure 3.2 shows the dependence of the maximum deflection on the number of finite elements in the model, and Figure 3.3 shows the deflection obtained with the finite volume model for one-way and two-way coupling cases. Finite element model it is considered converged for the so called 'fine' mesh. The one-way coupling underestimates the deflection, as compared to the two-way coupling by $17.0 \%$ for finite volume solver and by $14.5 \%$ for finite element solver. Two-way coupling gives a greater deflection in all considered tests. The fine fluid mesh captures smaller-scale variations in the velocity profile and pressure distribution, which influences the deflection magnitude. When the deflection increases, especially in the middle of the leading edge, the channel thicknesses also change, leading to an increase in the hydrodynamic pressure applied to the plate. Only a fully coupled model can account for this interaction. Also, the results obtained with STAR-CCM+ and LS-DYNA compare well with each other, with LS-DYNA giving a $4.6 \%$ greater estimate. The plots in Figure 3.3 follow the same pattern, with the two-way coupled model giving higher deflections than the one-way coupled model. The difference is that the finite volume model has not yet converged for the 'fine' mesh. For this reason, an additional model was run with finite volume discretization with an 'extra fine' grid. An 'extra fine' grid was built for the finite volume model with 6 by 800 by 1600 finite volumes representing the plate. Figure 3.4 presents a comparison of the maximum deflection for all tested models, as a function of the number of degrees of freedom. 


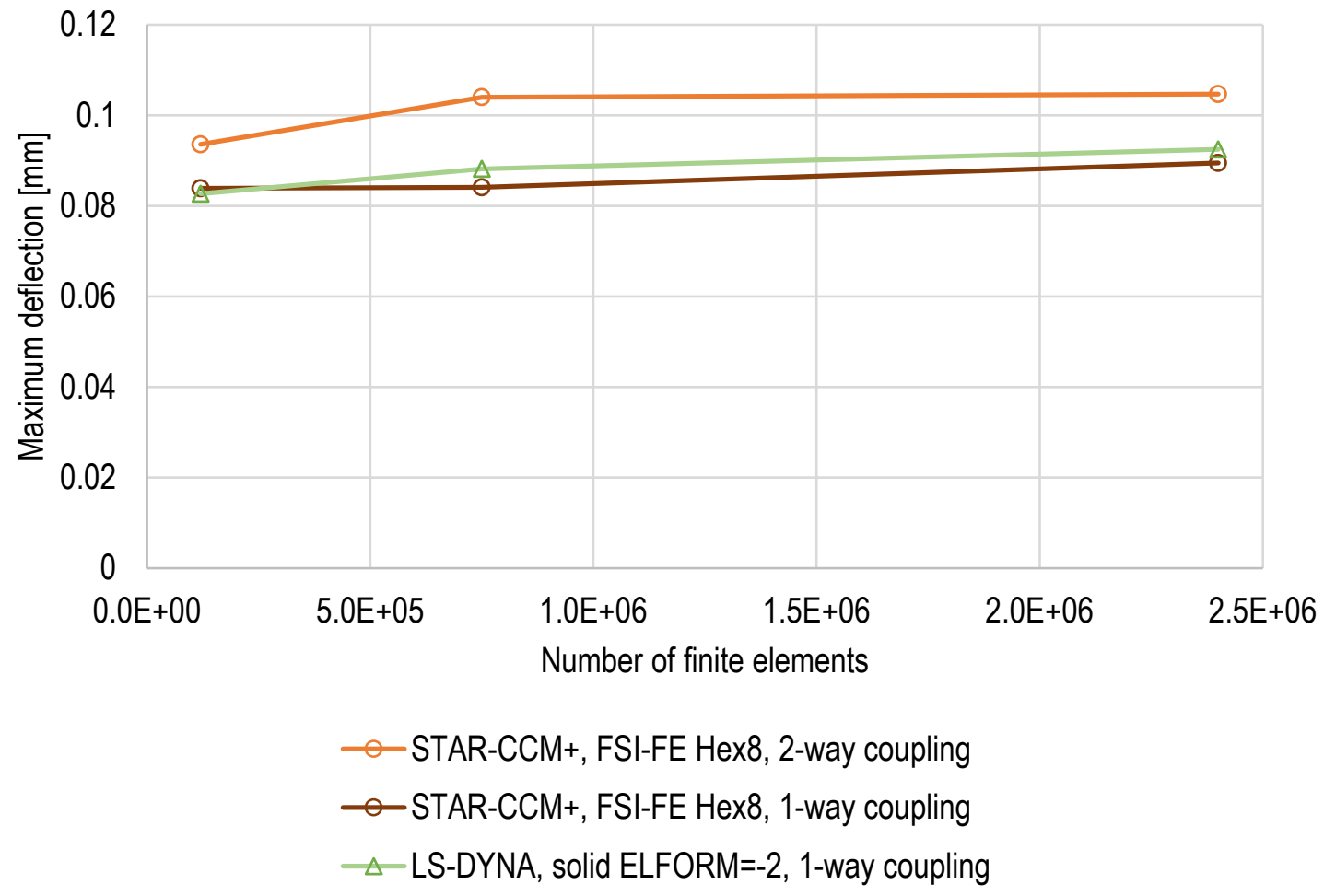

Figure 3.2. Convergence of the maximum deflection of a flat fuel plate modeled with solid finite elements.

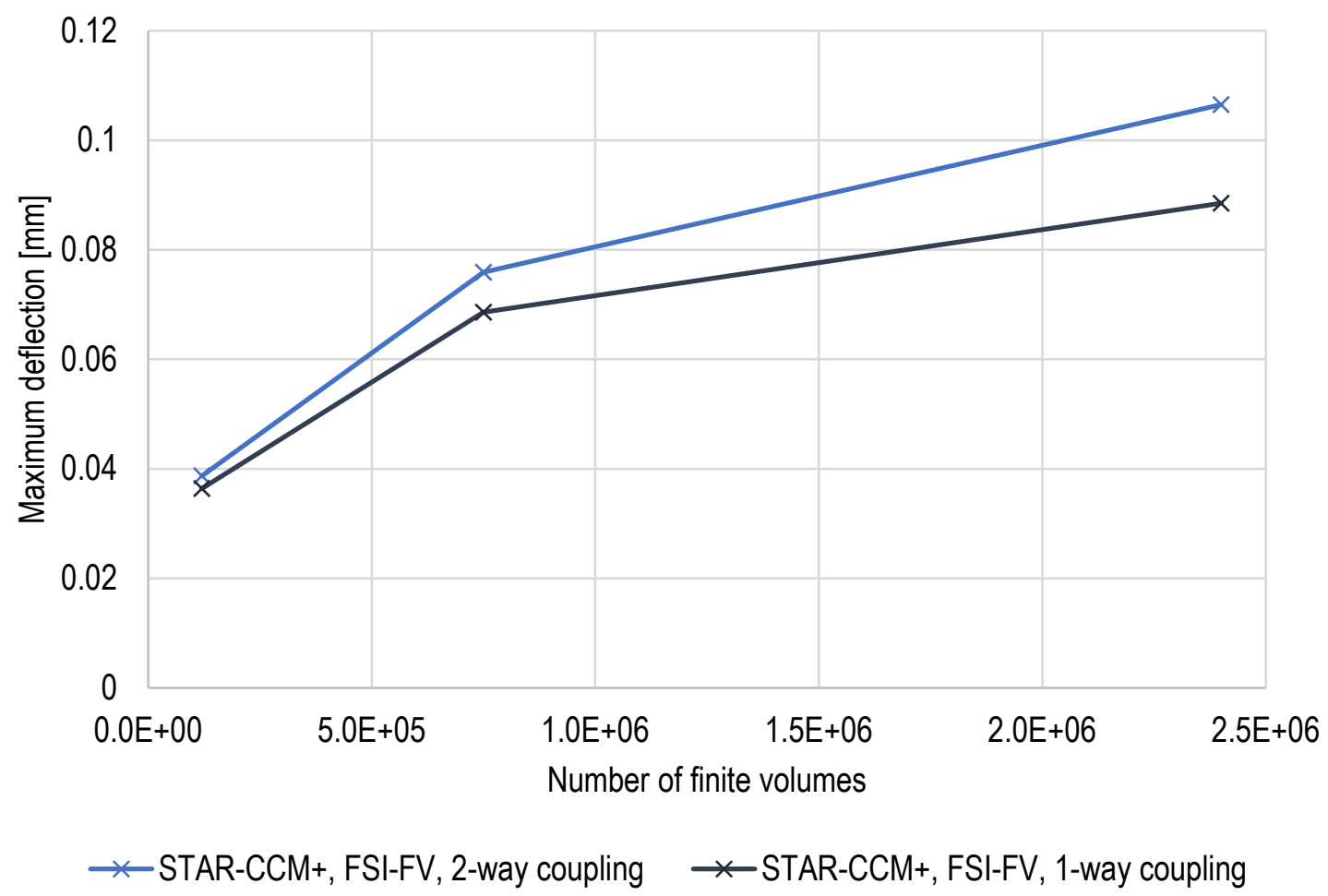

Figure 3.3. Convergence of the maximum deflection of a flat fuel plate modeled with solid finite volumes. 


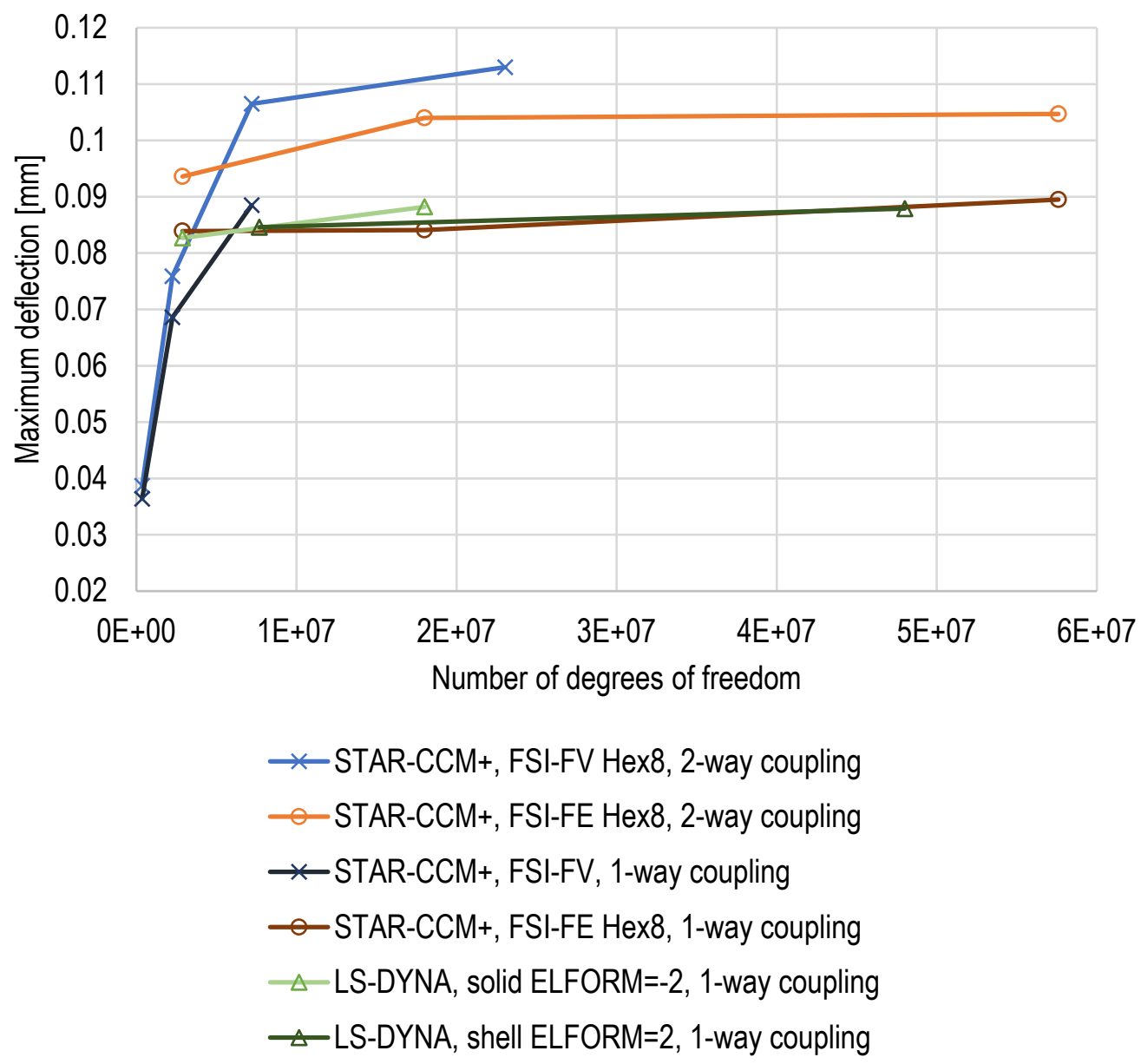

Figure 3.4. Convergence of the maximum deflection of a flat fuel plate modeled with solid finite elements and finite volumes as a function of the number of degrees of freedom.

\subsection{Cylindrical Plate}

The deflections of a cylindrical plate are analyzed for two values of plate thickness, $0.41 \mathrm{~mm}$ and 0.66 $\mathrm{mm}$. As an example, the 0.41-mm-thick plate is shown in Figure 2.6 and the dimensions are collected in Table 2.2. The discretization used in this example was derived in a mesh sensitivity study for a model for which the finite volume solid stress solver was used [5]. The computational grid consists of 6 by 500 by 800 cells. As mentioned before, the finite volume method requires a finer grid to obtain a mesh-independent result than the finite element method. For this reason, no additional mesh sensitivity study for the FEM model was performed.

The plates were subjected to three different magnitudes of hydrodynamic loading, resulting from varying coolant velocity. Figure 3.5 shows an example deflection contour plot of a 1.02-mm-thick cylindrical plate under hydrodynamic loading produced by flow at $9 \mathrm{~m} / \mathrm{s}$ average channel velocity. The considered cases differ with the ratio of plate maximum deflection magnitude to plate thickness and cover a range up to 0.2 , which significantly exceeds the expected conditions.

Table 3.2 presents the maximum deflections of the plates computed with the use of finite elements and finite volumes in STAR-CCM+ and for a few cases with the use of solid finite elements in LS-DYNA to get a code-to-code comparison. 


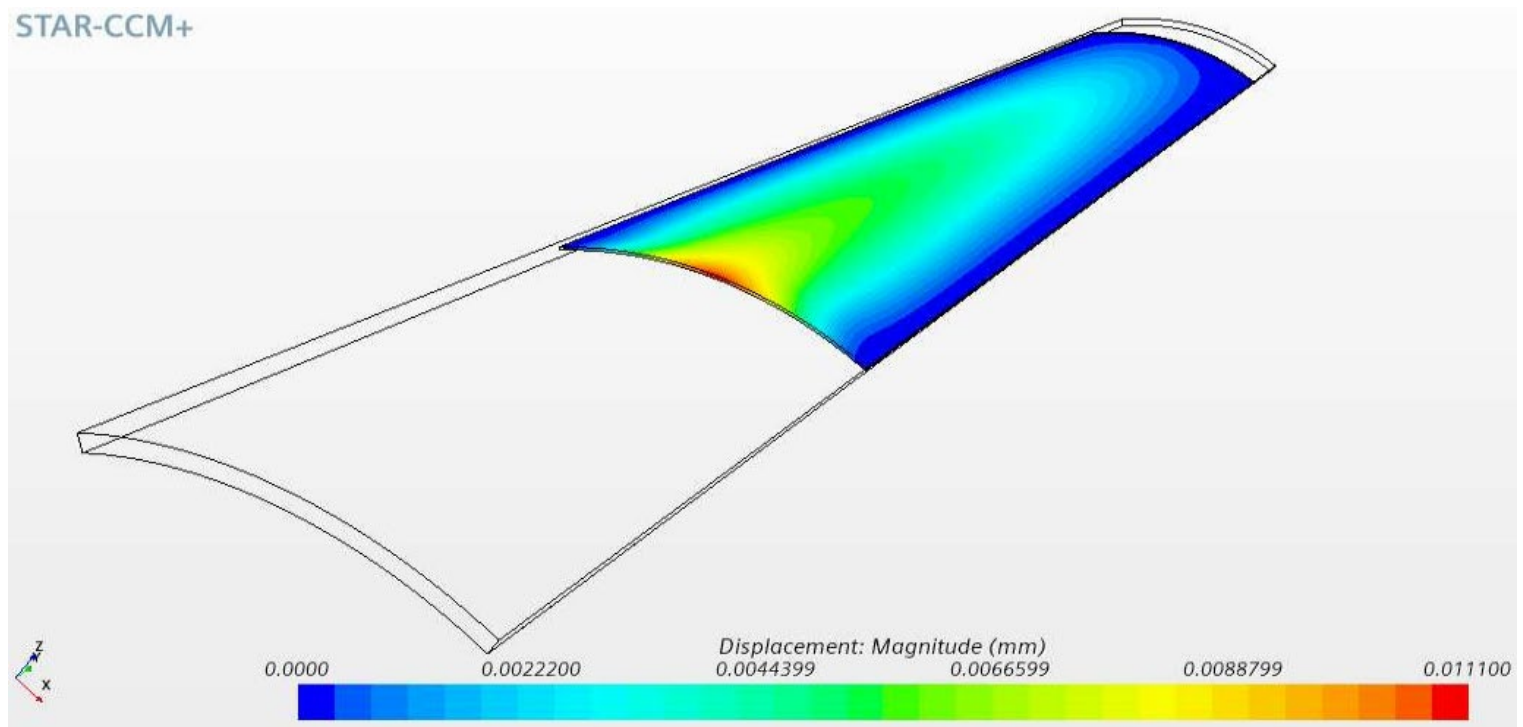

Figure 3.5. Example deflection contour plot of a cylindrical plate.

Table 3.2. Maximum deflection of a cylindrical plate.

\begin{tabular}{|c|c|c|c|c|c|}
\hline & & & \multicolumn{2}{|c|}{ STAR-CCM+ } & \multirow{2}{*}{$\begin{array}{c}\text { LS-DYNA } \\
\text { max } \\
\text { deflection, } \\
\text { d_max_FEM } \\
\text { [mm] }\end{array}$} \\
\hline $\begin{array}{c}\text { plate } \\
\text { thickness, } \\
\text { t [mm] }\end{array}$ & $\begin{array}{c}\text { inlet } \\
\text { velocity } \\
{[\mathrm{m} / \mathrm{s}]}\end{array}$ & $\begin{array}{c}\text { channel } \\
\text { velocity } \\
{[\mathrm{m} / \mathrm{s}]}\end{array}$ & $\begin{array}{c}\text { max } \\
\text { deflection, } \\
\text { d_max_FV } \\
{[\mathrm{mm}]}\end{array}$ & 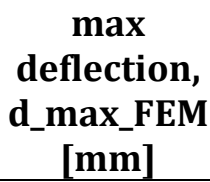 & \\
\hline \multirow{3}{*}{0.4064} & 5.00 & 5.44 & 0.0216 & 0.02117 & - \\
\hline & 7.35 & 8.00 & 0.0542 & 0.0471 & - \\
\hline & 8.27 & 9.00 & 0.0818 & 0.0613 & 0.0788 \\
\hline \multirow{4}{*}{0.6604} & 5.00 & 5.53 & 0.00353 & 0.0036 & - \\
\hline & 7.86 & 9.00 & 0.009 & 0.0089 & 0.00855 \\
\hline & 9.00 & 9.96 & 0.0115 & 0.0118 & - \\
\hline & 13.10 & 15.00 & 0.0262 & 0.026 & - \\
\hline
\end{tabular}




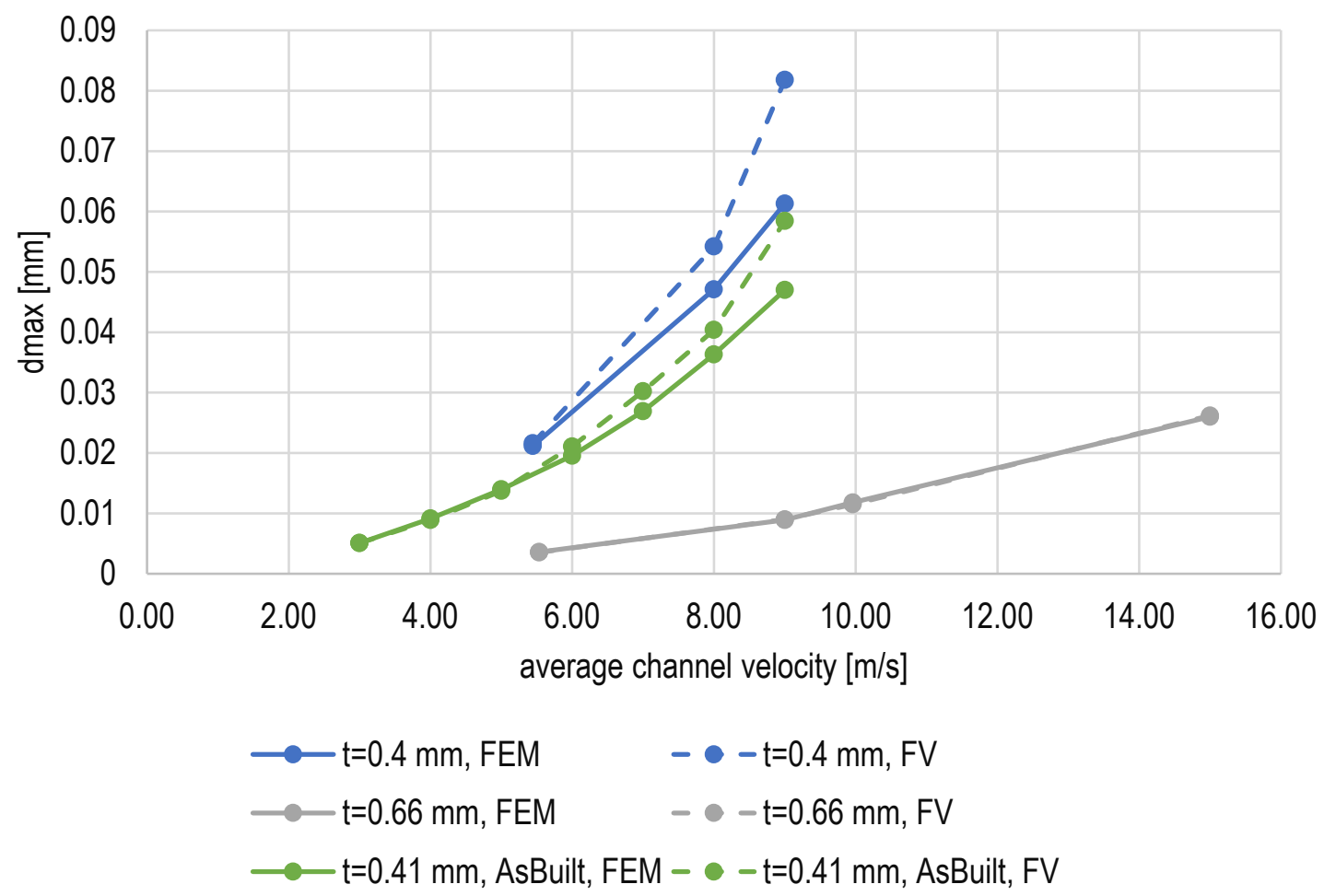

Figure 3.6. Relationship between the maximum deflection of the cylindrical plate and average channel velocity for varying plate thickness.

The obtained results were presented as a plot of the maximum deflection, $d_{\max }$ vs. average channel velocity, see Figure 3.6. As expected, the deflection increases with increasing coolant velocity and decreasing plate thickness. It is also significant that finite element method in each case gives lower deflections than finite volume method, which confirms the findings of the flat plate analysis. To better represent the relative difference between the finite element method and finite volume method models, the ratio of maximum deflection to plate thickness, $d_{\max } / t$ was computed with the use of finite volume and finite element solvers. Figure 3.7 presents a plot of $d_{\max , F E} / t$ vs. $d_{\max , F v} / t$. Both methods give similar results when the deflections constitute up to $5 \%$ of the thickness of the plate (see Figure $3.7(\mathrm{~b})$ ). The finite volume method gives greater deflections than the finite element solver for bigger ratios. This trend is the most noticeable for thin plates at high loads (check the blue line for $\mathrm{t}=0.4$ $\mathrm{mm}$ ). The reason is that the finite volume method solves the equations at cell centers, which are half a cell width away from constraints, loading, etc., without any numerical methods to account for that distance to the wall or boundary from the cell center. Therefore, with the plates being thinner by a cell thickness, the deflections are larger. 
(a)

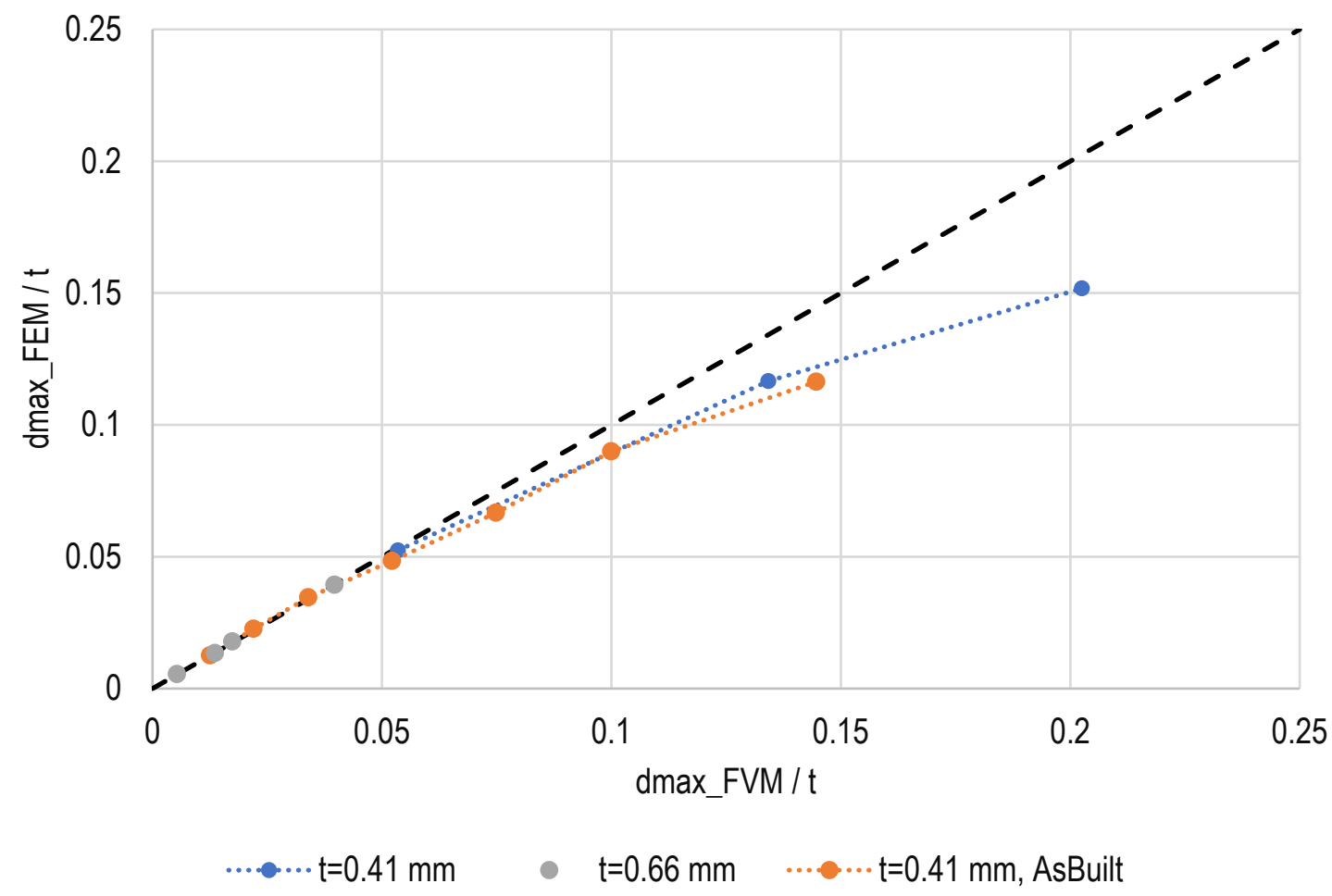

(b)

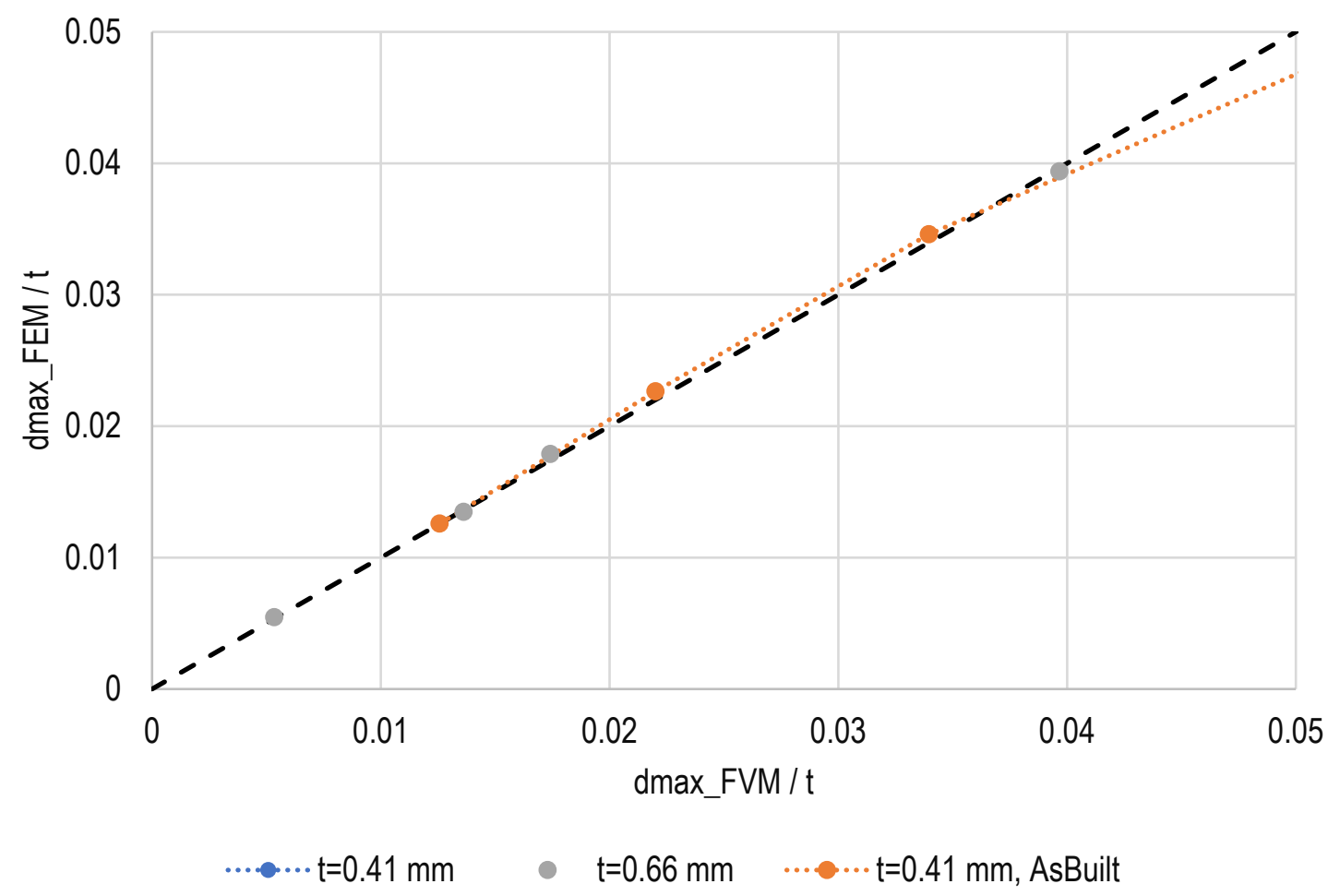

Figure 3.7 Comparison of the ratio of the maximum cylindrical plate deflection to plate thickness obtained with finite element and finite volume solvers (a) full range of values, (b) close-up to the 0 to 0.05 range. Dashed line is identity line. 


\subsection{Involute Plate}

In the present study, the computational model of the fluid-structure interaction between coolant and an involute plate, presented in Section 2.3, was recreated with a few differences. The model was simplified by removing the additional sections of the upstream and downstream regions with cyclic boundary conditions, as their influence on the velocity profile was small [15]. The authors of the reference paper showed that the use of the realizable k- $\varepsilon$ turbulence model resulted in only slightly smaller deflection than that of the model with the k- $\omega$ turbulence ( 0.082 mil instead of 0.085 mil). Therefore, the realizable $\mathrm{k}-\varepsilon$ model was used in this report for consistency purposes.

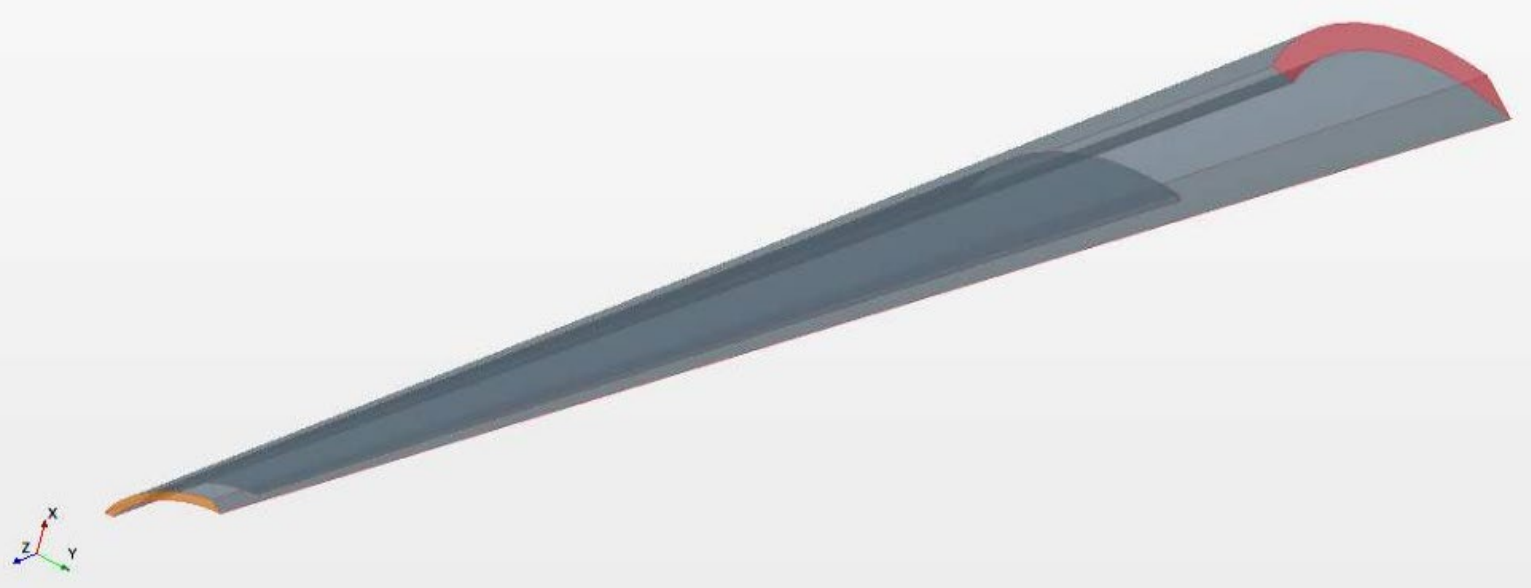

Figure 3.8. Geometry of the involute plate model.

The geometry of the new model is shown in Figure 3.8. With respect to the fluid solver, the surface marked in red is the velocity inlet boundary condition, the surface marked in orange is the pressure outlet boundary condition, and surfaces in grey are wall boundary conditions. Side surfaces of the involute have all displacement vector components constrained and all the remaining surfaces have freedom of movement.

A mesh sensitivity study was performed for an involute plate $1.05 \mathrm{~mm}$ thick, $0.075 \mathrm{~m}$ wide, and 0.87 $m$ long, in which the number of cells in the direction along the length was 200, in the thickness direction was 6 , and varied along the arc length from 50 to 200 . Table 3.3 combines the results obtained using finite element method and finite volume method for the plate with the same grid densities, denoted as coarse, medium, and fine. Figure 3.9 shows the dependence of the solution on the number of degrees of freedom along the arc length of the involute plate. At the average channel velocity of $13.37 \mathrm{~m} / \mathrm{s}$, the solution obtained with finite element method converges for the 'medium' mesh density. The finite volume model was discretized additionally with an 'extra fine' grid, to obtain a grid-independent solution. However, the converged solution underestimates the deflection as compared to that obtained with the finite element method.

Table 3.3. Convergence of the maximum deflection of an involute plate in STAR-CCM+.

\begin{tabular}{|c|c|c|c|}
\hline Mesh density & $\begin{array}{c}\text { Number of computational cells } \\
\text { along the arc length }\end{array}$ & $\mathbf{d}_{\text {max,Fv }}[\mathbf{m m}]$ & $\mathbf{d}_{\text {max,FE }}[\mathbf{m m}]$ \\
\hline coarse & 50 & 0.00415 & 0.0267 \\
\hline medium & 100 & 0.00536 & 0.0263 \\
\hline fine & 200 & 0.00623 & 0.0264 \\
\hline extra fine & 400 & 0.00629 & - \\
\hline
\end{tabular}




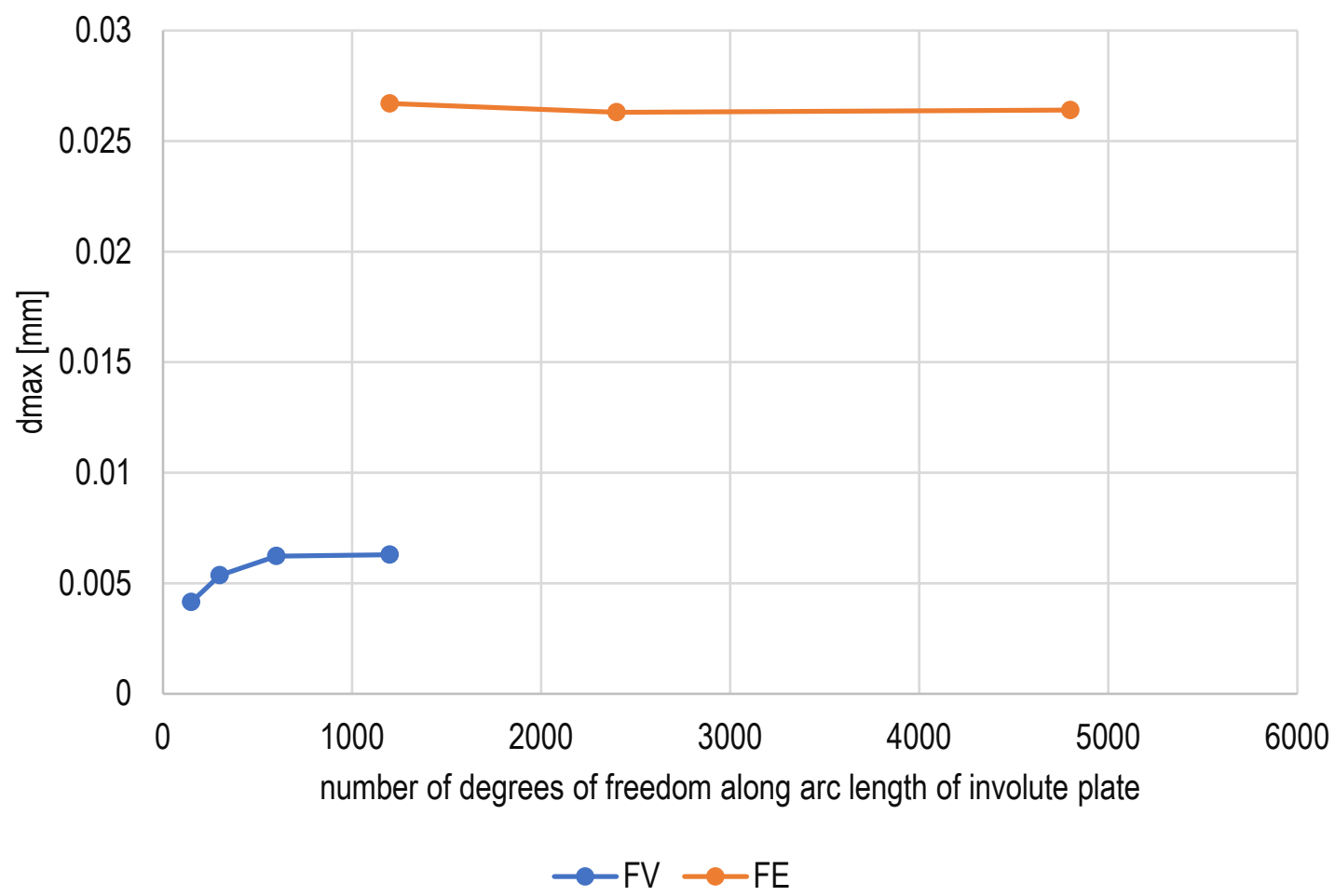

Figure 3.9. Convergence of finite element and finite volume meshes for an involute plate as a function of the number of degrees of freedom along arc length of involute plate.

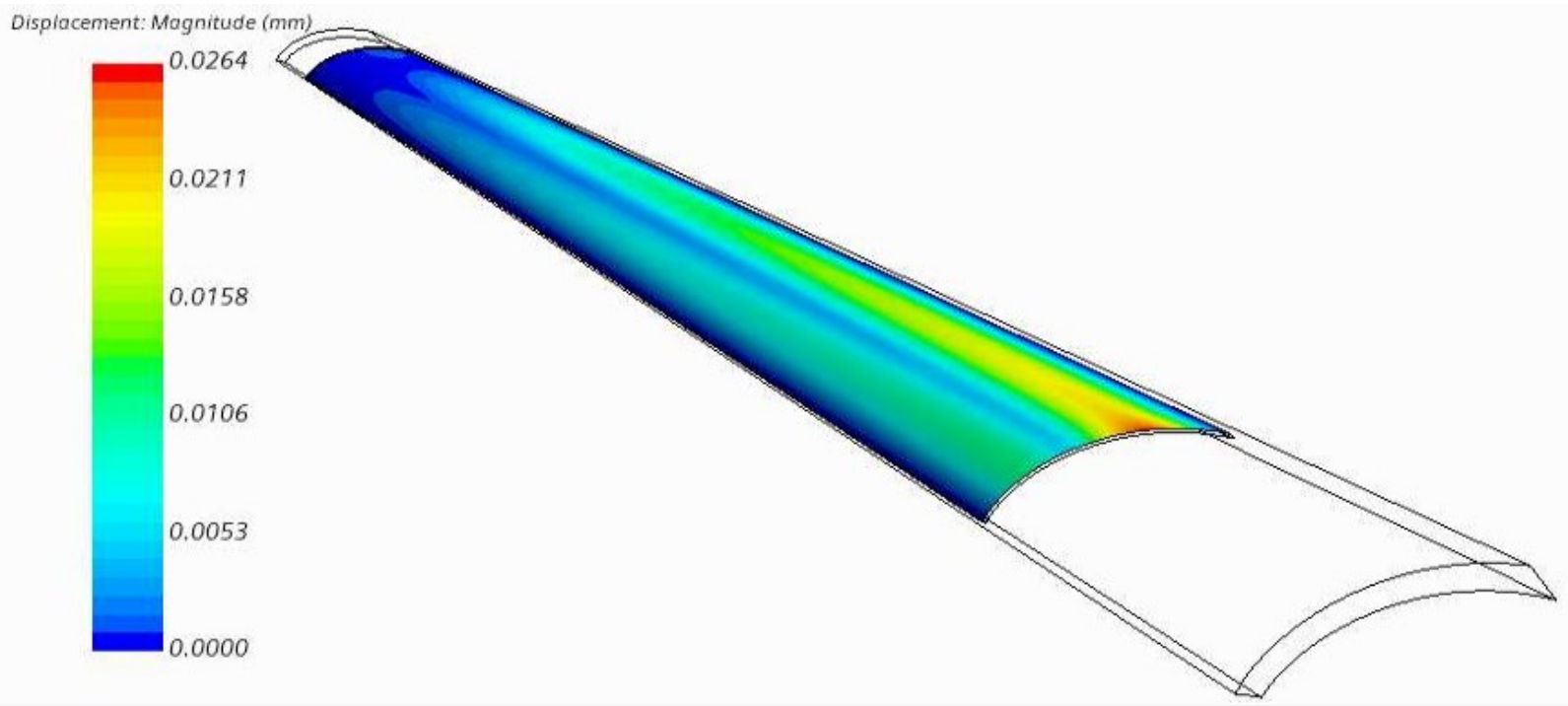

Figure 3.10. Example deflection contour plot of an involute plate.

Figure 3.10 presents a contour plot of involute plate deflections obtained with the 'fine' mesh, which compares well with the deformation obtained in [15] which is shown in Figure 2.9. 
A set of runs for the involute plate model performed with the 'fine' mesh covers inlet velocities: 5, 10, $16 \mathrm{~m} / \mathrm{s}(6.01,12.02,19.22 \mathrm{~m} / \mathrm{s}$ average channel velocity). The additional data point was added for an average channel velocity of $16.0 \mathrm{~m} / \mathrm{s}$, which was used in reference [15]. Table 3.4 lists the coolant velocities and corresponding maximum deflections obtained with finite element and finite volume models.

Table 3.4. Maximum deflection of an involute plate.

\begin{tabular}{|c|c|c|c|}
\hline & & \multicolumn{2}{|c|}{ STAR-CCM+ } \\
\hline $\begin{array}{c}\mathbf{V}_{\text {inlet }} \\
{[\mathbf{m} / \mathbf{s}]}\end{array}$ & $\begin{array}{c}\mathbf{V}_{\text {channel }} \\
{[\mathbf{m} / \mathbf{s}]}\end{array}$ & $\mathbf{d}_{\text {max,Fv }}[\mathbf{m m}]$ & $\mathbf{d}_{\text {max,FE }}[\mathbf{m m}]$ \\
\hline 5.0 & 6.0 & 0.00098 & 0.0030 \\
\hline 10.0 & 12.0 & 0.00364 & 0.0109 \\
\hline 13.3 & 16.0 & 0.00637 & 0.0186 \\
\hline 16.0 & 19.2 & 0.00897 & 0.0264 \\
\hline
\end{tabular}

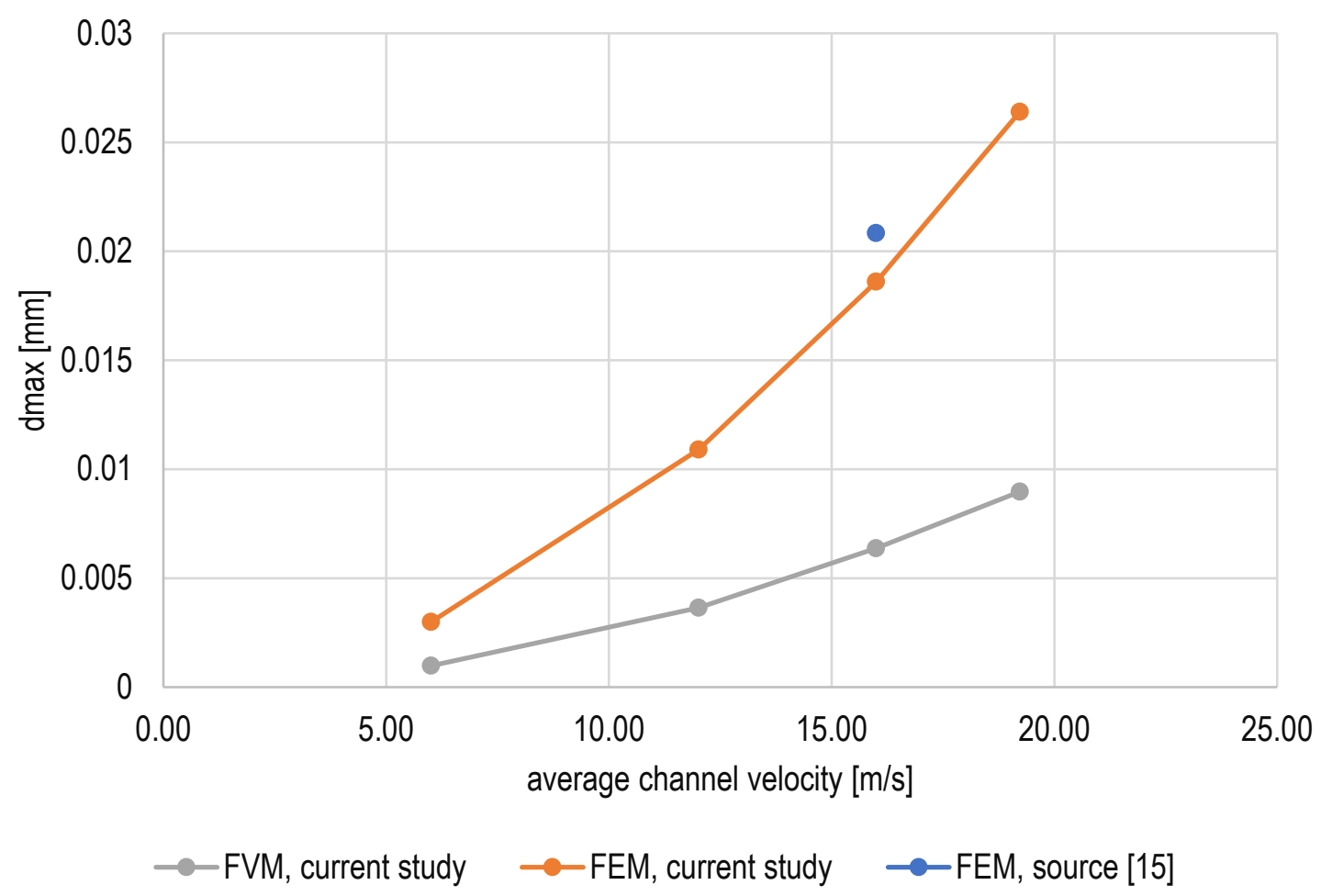

Figure 3.11 Comparison of the maximum involute plate deflection presented in [15] and obtained in the current study.

Data points from Table 3.4 were plotted alongside of the maximum deflection obtained by Bojanowski et al. [15] in Figure 3.11. For the average channel velocity of $16 \mathrm{~m} / \mathrm{s}$, the previous study gave the maximum deflection $\mathrm{d}_{\max }=0.0208 \mathrm{~mm}$, whereas the current model gave $\mathrm{d}_{\max , \mathrm{FE}}=0.0186 \mathrm{~mm}$ when FEM was used ( $89 \%$ of the benchmark solution), and $\mathrm{d}_{\mathrm{max}, \mathrm{Fv}}=0.00637 \mathrm{~mm}$ when finite volume solver was used (31\% of the benchmark solution).

Figure 3.12 presents a comparison of the ratios obtained with the finite element and finite volume methods. All data points fall within the range of the maximum deflection to plate thickness ratio 
between 0 and 0.05 , which is in the lower end of the range analyzed for the cylindrical plate. The figure noticeably differs from a corresponding plot for the cylindrical plate in Figure 3.7. All four data points fall on the left side of the identity line. The finite volume solution is significantly smaller than the finite element solution. As mentioned in Section 3.2, the solution for a cylindrical plate for small values of $d_{\max } / t$ was very similar irrespective of the used method. The reason is that the models were discretized with a grid obtained from a mesh sensitivity study for a finite volume model. In the case of an involute plate model, the analysis started with the finite element model, which, as shown in Figure 3.9, gives a mesh independent solution even for the coarse mesh, whereas for the same computational grid, the finite volume solution is not converged and therefore significantly lower.

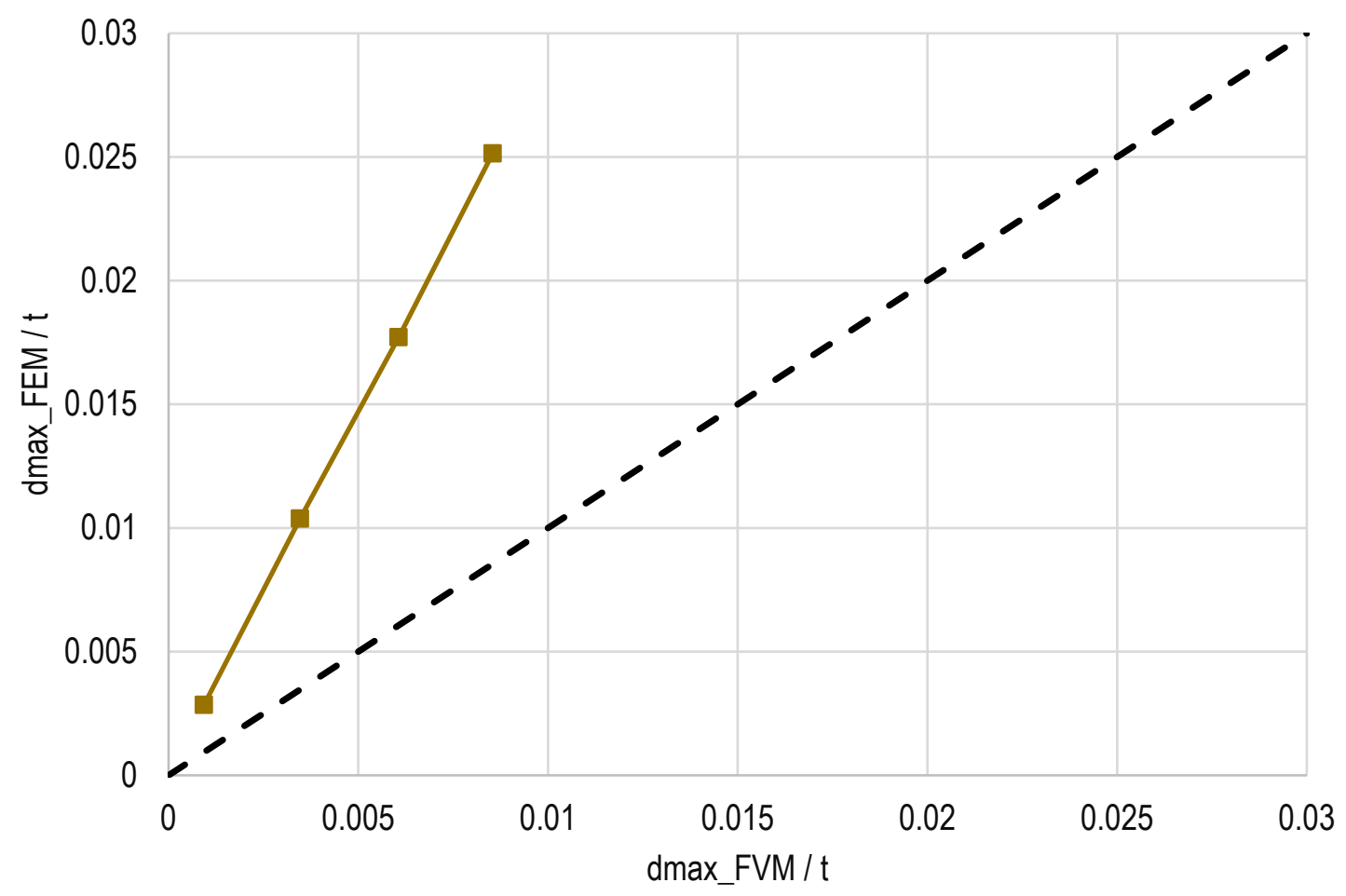

Figure 3.12. Comparison of the ratio of the maximum involute plate deflection to plate thickness obtained with finite element and finite volume solvers. Dashed line is identity line. 


\section{Conclusions}

The present report focuses on a comparison of finite volume and finite element methods to model solids in fluid-structure interaction problems with the goal to estimate the flow-induced fuel plate deflections obtained with the two methods. The finite volume method will be obsoleted in STARCCM+ by the end of 2021, nevertheless, this evaluation is important because the method was used by ANL researchers to model the response of the fuel plates, despite its drawbacks, which are discussed in the report. It was essential to check how those estimates compare to the results obtained with the finite element method that is considered superior for structural analysis.

The comparison shows that, independently of the plate geometry, the finite volume method significantly underestimates the deflection as compared to finite element method for coarser meshes. When the discretization is developed as a result of a mesh sensitivity study using finite element method, the result obtained using finite volume method can be a few times smaller than the corresponding finite element method solution. For example, for an involute plate, the max finite volume deflection was three times smaller than the maximum deflection obtained with finite elements. On the other hand, to achieve a mesh independent solution using finite volume method, the mesh needs to be very fine, and in this case the maximum deflection tends to be greater than when finite element method is used.

A STAR-CCM+ and LS-DYNA code-to-code comparison was performed. Two types of finite element formulations were used in LS-DYNA: a solid and a shell finite elements. Mesh sensitivity study showed that both approaches converge to a similar value, slightly greater than that obtained with STAR-CCM+ finite element solver.

The evaluation of the methods was extended by adding two benchmark cases from STAR-CCM+ Verification Suite [4], [10], representing a cantilever beam and thin curved shell in bending. The problems were solved with finite volume and finite element methods, and the results confirmed the previously discussed findings.

The analysis shows that the finite element solver is superior to the finite volume solver in terms of representation of model geometry and estimating the structural behavior of fuel plates. Depending on the ratio of the load to the flexibility of the plate, the finite volume solver can greatly under- or overestimate the structural response if an appropriate mesh is not used. 


\section{References}

1. Oak Ridge National Laboratory, "High Flux Isotope Reactor", https://neutrons.ornl.gov/hfir last accessed July 23, 2018.

2. Institut Laue-Langevin, "The ILL High-Flux reactor", https://www.ill.eu/reactor-and-safety/highflux-reactor/, last accessed July 23, 2018.

3. Technical University of Munich, "Research Neutron Source Heinz Maier-Leibnitz (FRM II)", https://www.frm2.tum.de/en/home/, last accessed July 23, 2018.

4. Simcenter STAR-CCM+ Documentation, https://documentation.thesteveportal.plm.automation.siemens.com/starccmplus latest en/ind ex.html?param=IzdGX\&authLoc=https://thesteveportal.plm.automation.siemens.com/Authoris eRedirect, last accessed November 2021.

5. A. Tentner, C. Bojanowski, E. Feldman, E. Wilson, G. Solbrekken, C. Jesse, J. Kennedy, J. Rivers, and G. Schnieders, "Evaluation of Thin Plate Hydrodynamic Stability through a Combined Numerical Modeling and Experimental Effort", ANL/RTR/TM-16/9, 2017.

6. M. Sitek, A. Bergeron, C. Bojanowski, Y. Yu, J. Licht, "Involute Working Group - Development and Validation of the Finite Element Models of the Cheverton-Kelley Experiments", ANL/RTR/TM20/15, 2020.

7. A. Bergeron, "Review of the Oak Ridge National Laboratory (ORNL) Neutronic Calculations Regarding the Conversion of the High Flux Isotope Reactor (HFIR) to the Use of Low Enriched Uranium (LEU) Fuel", ANL/RERTR/TM-12/49, Argonne National Laboratory, 2012.

8. A. Bergeron, "Neutronic Conversion Analyses of the Laue-Langevin Institute (ILL) High Flux Reactor (RHF)", ANL/GTRI/TM-14/15, Argonne National Laboratory, 2014.

9. A. Rohrmoser, "Core Model of New German Neutron Source FRM II", Nuclear Engineering and design 240 pp. 1417-1432, 2010.

10. Reduced Enrichment for Research and Test Reactor, "International Meeting on Reduced Enrichment for Research and Test Reactors", last accessed October 29, 2019.

11. A. Bergeron et al., "Involute Working Group - Progress towards Validation of CFD for Involute-Plate Reactors Safety Analysis", RERTR 2019, 40 th International Meeting on Reduced Enrichment for Research and Test Reactors. Zagreb, Croatia, Oct. 6-10, 2019.

12. J.M. Gere, S.P. Timoshenko, "Mechanics of Materials Fourth Edition", PWS Publishing Company, 1997.

13. O.C. Zienkiewicz, R.I. Taylor, J.Z. Zhu., "The Finite Element Method: Its Basis and Fundamentals, 7th Edition", Hardcover ISBN: 9781856176330, eBook ISBN: 9780080951355, ButterworthHeinemann, 2013.

14. R. D. Cheverton, W. H. Kelley, "Experimental Investigation of HFIR Fuel Plate Deflections Induced by Temperature and Pressure Differentials", ORNL-TM-2325, 1968.

15. C. Bojanowski, A. Bergeron, M. Sitek, Y. Yu, J. Licht, "Fluid Structure Interaction Analysis for Involute Fuel Plates”, 2020 ANS Virtual Winter Meeting, 2020.

16. https://www.dynasupport.com/manuals/ls-dyna-manuals/ls-dyna-manual-r-7.1-vol-i/view, last visited November 2021)

17. S. P. Timoshenko, J. N. Goodier, "Theory of Elasticity, 3rd Ed.”, McGraw-Hill, 1982.

18. R.H. MacNeal., "Finite elements: their design and performance", ISBN 0-8247-9162-2, Marcel Dekker, Inc., 1994. 


\section{Acknowledgement}

This work was sponsored by the U.S. Department of Energy, Office of Material Management and Minimization in the U.S. National Nuclear Security Administration Office of Defense Nuclear Nonproliferation under Contract DE-AC02-06CH11357. 


\section{APPENDIX A: Verification Test Cases}

Two test cases from the STAR-CCM+ Verification Suite [4] were selected to extend the comparative analysis of the finite volume and finite element methods used for modeling solids. A list of STAR-CCM+ software capabilities and relevant verification approach are presented in Table A.1.

Table A.1. List of STAR-CCM+ software capabilities and relevant verification approach [4].

\begin{tabular}{|c|c|c|c|}
\hline SM-1 & $\begin{array}{l}\quad \begin{array}{l}\text { Bending of a Cantilever } \\
\text { Beam }\end{array} \\
\text { This is a basic structural } \\
\text { capability used to predict } \\
\text { bending deflections of solids } \\
\text { due to external load (like fuel } \\
\text { plates loaded with pressure } \\
\text { differential). }\end{array}$ & $\begin{array}{l}\text { The results of the simulation } \\
\text { are compared with the } \\
\text { analytical solution presented } \\
\text { in reference [9]. }\end{array}$ & $\begin{array}{l}\text { SM- } \\
\text { 1_Bending_Of_Cantilever_Beam. } \\
\text { sim }\end{array}$ \\
\hline SM-2 & $\begin{array}{l}\quad \begin{array}{l}\text { 3D Shell Deformation } \\
\text { Analysis }\end{array} \\
\text { This capability is used to } \\
\text { predict deformations of thin } \\
\text { 3D structures (like fuel plates) } \\
\text { due to external loads. }\end{array}$ & $\begin{array}{l}\text { Verification test problems are } \\
\text { compared with NAFEMS } \\
\text { benchmark collections [10]. }\end{array}$ & SM-2_Shell_Deformation.sim \\
\hline
\end{tabular}

These two simulations, among others, are a part of Argonne's software verification process, which is performed for each new release. The results for STAR-CCM+ v. 2020.2 were previously published in [4]. Here, the analysis is repeated for the finite element method and supplemented with results obtained with finite volume method, using the same discretization, to show the differences in solutions depending on the computational method.

\section{A.1 SM-1. Finite Element Bending of a Cantilever Beam}

This case is a validation of the exact Timoshenko solution of bending of a cantilever under plane strain conditions [17], which are represented with the use of symmetry boundary conditions on the short sides of the beam cross-section. The simulation calculates displacements and stresses in a cantilevered rectangular beam that is subjected to pressure loads. Additionally, the beam is rotated along its axis to test if the result is independent of the coordinate system. The beam is loaded with a parabolic shear stress using the continuous option for the traction load on the right end face. The constraints on the left end of the beam are based on the exact solution, which allows for some rotation of the beam. The edges of the beam cross-section are not aligned with the laboratory coordinate system but are at a $45^{\circ}$ angle as shown in Figure A.1. In this coordinate system, the loaded end is at $\mathrm{x}_{\mathrm{loc}}=0 \mathrm{~m}$ and the free end is at $\mathrm{x}_{\mathrm{loc}}=30 \mathrm{~m}$. The beam thickness is $1.0 \mathrm{~m}$ and height $2 \mathrm{~m}$. All simulation input parameters are presented in Table A.2.

The simulation file provided by Simcenter STAR-CCM+ contains a model discretized with 30 by 2 by 1 Hex20 hexahedral finite elements with quadratic shape functions. The same discretization was used for the Hex8 finite element formulation with linear shape functions, as well as finite volume cells to show the sensitivity of the solution to the selection of the solver. 
(a)

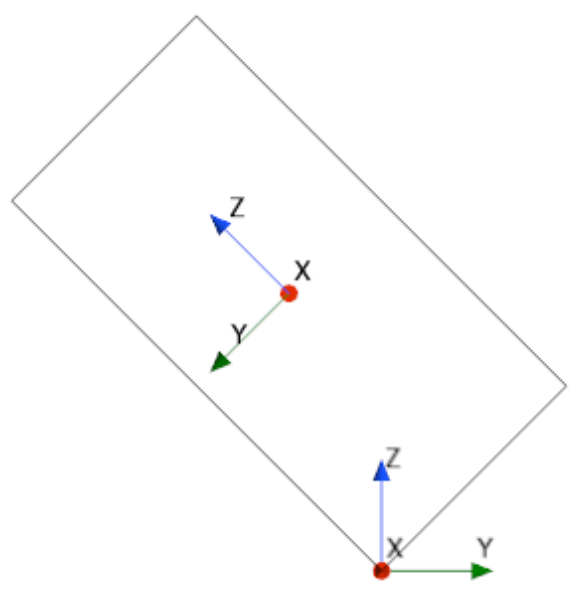

(b)

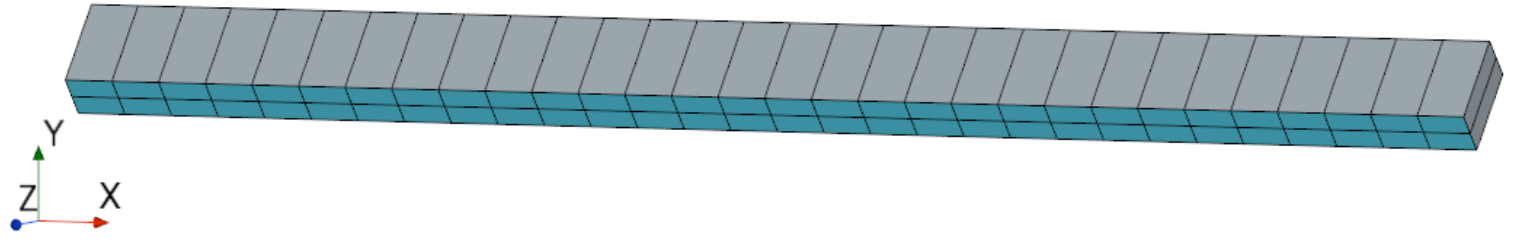

Figure A.1. Geometry of the model for case SM-1 (a) the cross-section, (b) view of the computational grid.

Table A.2. Input parameters for test case SM-1.

\begin{tabular}{|c|c|}
\hline Geometry: & $\begin{array}{l}\text { The cross section is rectangular with dimensions } 1.0 \mathrm{~m} \text { by } 2.0 \mathrm{~m} \text {, } \\
\text { rotated counterclockwise by } 45 \text { degrees around the global X axis }\end{array}$ \\
\hline Material properties: & $\begin{array}{l}\text { Linear elastic isotropic material model with: } \\
\text { - Young's modulus }=900 \mathrm{GPa} \\
\text { - Poisson's ratio }=0.3 \\
\text { - } \quad \text { Density }=2702 \mathrm{~kg} / \mathrm{m}^{3} \\
\end{array}$ \\
\hline Physics Models: & $\begin{array}{ll}\text { - } & \text { Linear Isotropic Elastic } \\
\text { - } & \text { Solid } \\
\text { - } & \text { Solid Stress/Finite Volume Solid Stress } \\
\text { - } & \text { Steady } \\
\text { - } & \text { Three Dimensional } \\
\end{array}$ \\
\hline $\begin{array}{l}\text { Finite Element } \\
\text { Formulation: }\end{array}$ & $\begin{array}{c}\text { Hexahedral FE: } \\
\text { - Hex8 } \\
\text { - Hex20 } \\
\end{array}$ \\
\hline Boundary Conditions: & $\begin{aligned} \bullet \quad \text { at } \mathrm{x}=30 \mathrm{~m} \text { displacement defined by following components: } & \\
U_{x} & =\frac{2 P y\left(1-v^{2}\right)}{E}\left(3 x^{2}-\left(\frac{2-v}{1-v}\right) y^{2}-3\left(l^{2}-\frac{1}{2(1-v)}\right)\right), \\
U_{y} & =\frac{2 P y\left(1-v^{2}\right)}{E}\left(-\frac{3 v}{1-v} x y^{2}-x^{3}+3 x l^{2}-2 l^{3}\right), \\
U_{z} & =0, \\
& \bullet \quad \text { at } \mathrm{x}=0 \mathrm{~m} \text { traction is defined as: } \\
P & =\int_{-\frac{h}{2}}^{\frac{h}{2}} 1.5 P\left(1-\left(\frac{2 y}{h}\right)^{2}\right) d y=10^{6} .\end{aligned}$ \\
\hline
\end{tabular}


In the verification process, the acceptance criteria for the solution are the unsigned relative differences between the result of the simulation and the analytical solution in maximum displacement in the local $Y$ direction, $\mathrm{U}_{\mathrm{Yloc}}$, and maximum axial stress, $\mathrm{S}_{\mathrm{xx}}$. The difference in maximum displacement should not exceed $0.1 \%$ and the difference in maximum bending stress should not be greater than $1 \%$.

The maximum displacement values of the free tip and the maximum stress values at the fixed boundary obtained analytically and from computations are collected in Table A.3. Hex20 finite elements give a 5-digit accuracy for stresses and a 7-digit accuracy for displacements., Hex8 finite elements estimate a smaller deflection and stress by approximately $25 \%$, and the finite volume method gives a $40.3 \%$ error in maximum displacements and $67.4 \%$ in maximum stresses.

Table A.3. Maximum displacements and stresses for Bending of a Cantilever Beam test.

\begin{tabular}{|c|c|c|c|c|c|}
\hline \multicolumn{2}{|c|}{ Method } & $\begin{array}{c}\text { Maximum vertical } \\
\text { displacement [mm] }\end{array}$ & $\begin{array}{c}\text { Relative } \\
\text { error }\end{array}$ & $\begin{array}{c}\text { Maximum axial } \\
\text { stress [MPa] }\end{array}$ & $\begin{array}{c}\text { Relative } \\
\text { error }\end{array}$ \\
\hline \multicolumn{2}{|c|}{ analytical [17] } & 109.1984 & - & 179.80 & - \\
\hline \multirow{2}{*}{ FEM } & Hex8 & 81.97 & $24.9 \%$ & 133.5 & $25.8 \%$ \\
\cline { 2 - 6 } & Hex20 & 109.1984 & $0.0 \%$ & 179.80 & $0.0 \%$ \\
\hline \multicolumn{2}{|c|}{ FVM } & 65.156 & $40.3 \%$ & 58.57 & $67.4 \%$ \\
\hline
\end{tabular}

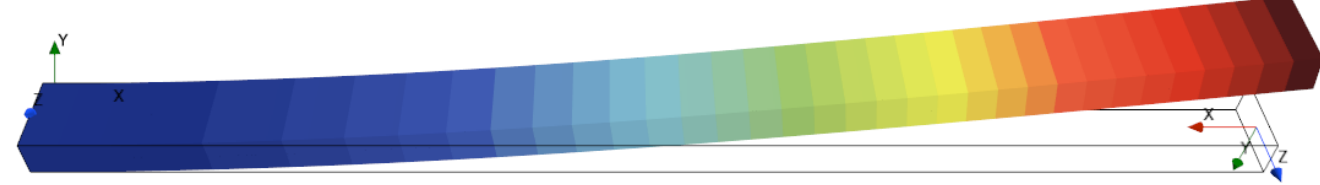

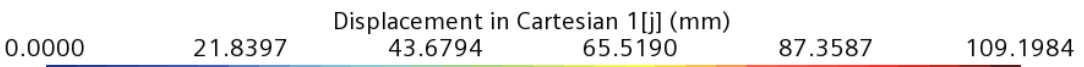

Figure A.2. Displacement field $U_{\text {Yloc }}$ of an elastic cantilevered beam modeled with Hex20 finite elements in structural mechanics case SM-1 (the deformation was scaled up to improve the readability of the figure).

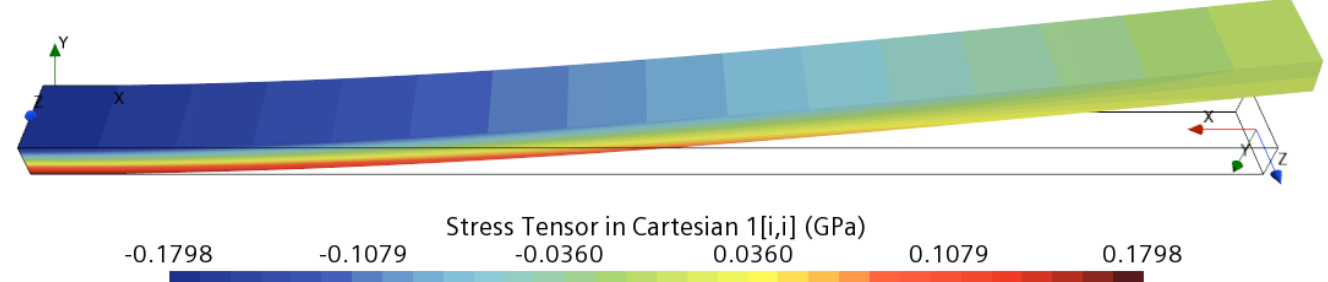

Figure A.3. Axial stress $S_{x x}$ field in an elastic cantilevered beam modeled with Hex 20 finite elements in structural mechanics case SM-1 (the deformation was scaled up to improve the readability of the figure). 


\section{A.2 SM-2. Scordelis-Lo Roof}

The Scordelis-Lo Roof case is a widely used benchmark test to check the accuracy of finite element types for curved shell problems in bending. This case comprises a moderately thin shell that is subject to gravity loading. It has inextensional bending modes which are a very important feature of this problem.

A quarter of a cylindrical roof is modeled with solid elements with appropriate boundary conditions and subjected to gravity load. The variable of interest is the vertical displacement of the point in the middle of the free edge, as presented in Figure A.4. The example is based on reference [18], where a linear elastic solution was given.

The model provided by Simcenter STAR-CCM+ is discretized with 10 by 10 by 2 Hex 8 hexahedral finite elements. The same discretization was used for the Hex20 finite element formulation, as well as finite volume cells.

(a)

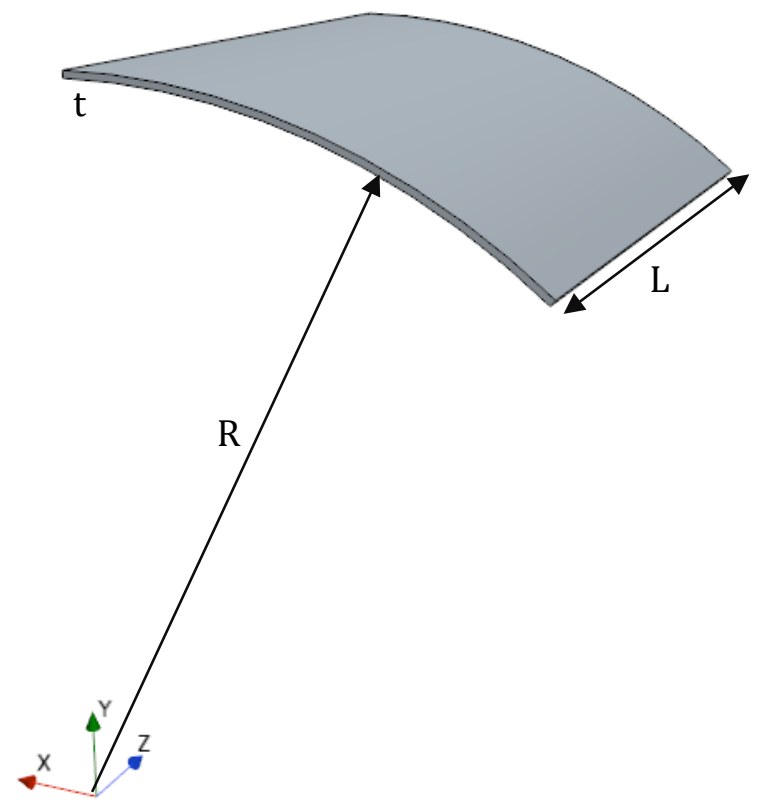

(b)

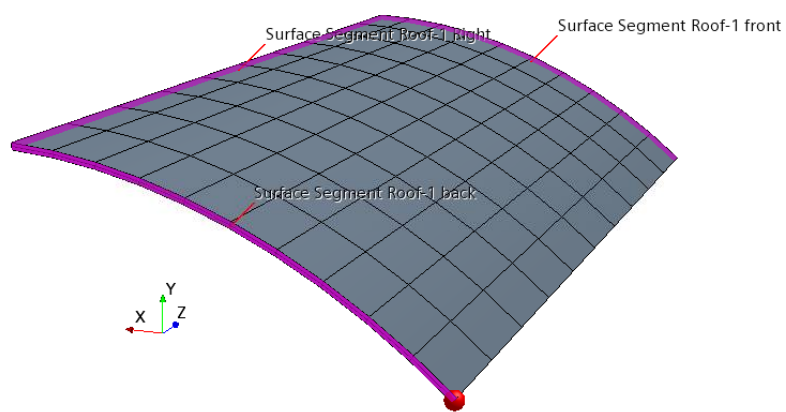

Figure A.4. Geometry description for case SM-2 (a) dimensions of the shell, (b) view of the computational grid.

Table A.4. Input parameters for test case SM-2.

\begin{tabular}{|c|c|}
\hline Geometry: & $\begin{array}{ll}\text { - } & \text { Roof length } 2 \mathrm{~L}=50 \mathrm{~m} \\
\text { - } & \text { Roof radius } \mathrm{R}=25 \mathrm{~m} \\
\text { - } & \text { Thickness } \mathrm{t}=0.25 \mathrm{~m} \\
\text { - } & \text { Domain extents }(\mathrm{m}): \mathrm{X}=16.23, \mathrm{Y}=44.4, \mathrm{Z}=25.0\end{array}$ \\
\hline Material properties: & $\begin{array}{l}\text { Linear elastic isotropic material model with } \\
\text { - Young's modulus } \mathrm{E}=432.0 \mathrm{MPa} \text {, } \\
\text { - Poisson's ratio }=0.0 \\
\text { - Density }=1.0 \mathrm{~kg} / \mathrm{m}^{3} \text {. }\end{array}$ \\
\hline Physics Models: & $\begin{array}{ll} & \text { Gravity } \\
\text { - } & \text { Linear Isotropic Elastic }\end{array}$ \\
\hline
\end{tabular}




\begin{tabular}{|c|c|}
\hline & $\begin{array}{ll}\text { - } & \text { Solid } \\
\text { - } & \text { Solid Stress/Finite Volume Solid Stress } \\
\text { - } & \text { Steady } \\
\text { - } & \text { Three Dimensional }\end{array}$ \\
\hline $\begin{array}{l}\text { Finite Element } \\
\text { Formulation: }\end{array}$ & $\begin{array}{ll}\text { Hexahedral FE: } \\
\text { - } \\
\text { - } & \text { Hex8 } 80 \\
\end{array}$ \\
\hline Body Load: & $\begin{array}{l}\text { - Gravitational acceleration: } \\
\mathrm{g}=[0.0,-360.0,0.0] \mathrm{m} / \mathrm{s}^{2}\end{array}$ \\
\hline Boundary Conditions: & $\begin{array}{l}\text { - Surface Segment Roof- } 1 \text { back - component of displacement in } \\
\text { z-direction }(\mathrm{m})=0.0, \\
\text { - Surface Segment Roof- } 1 \text { front - component of displacement in } \\
\text { x-direction }(\mathrm{m})=0.0 \text { and in y-direction }(\mathrm{m})=0.0 \text {, } \\
\text { - Surface Segment Roof-1 Right - component of displacement in } \\
\text { x-direction }(\mathrm{m})=0.0\end{array}$ \\
\hline
\end{tabular}

The reference deflection of a point on the roof in the negative Y direction is $0.3024 \mathrm{~m} \mathrm{[18].} \mathrm{The}$ computational solution obtained with finite element solver in STAR-CCM+ is $1.5 \%$ lower than the reference when Hex8 element is used, and $0.3 \%$ lower when Hex20 elements are used. On the other hand, the finite volume method gives an overly-stiff response, with an $88.5 \%$ error, if the same discretization is used.

Table A.5. Vertical displacement of a point on the free edge for Scordelis-Lo Roof test.

\begin{tabular}{|c|c|c|c|}
\hline \multicolumn{2}{|c|}{ Solution } & $\begin{array}{c}\text { Vertical displacement of the } \\
\text { point on the free edge [m] }\end{array}$ & Relative error \\
\hline \multicolumn{2}{|c|}{ reference [18] } & 0.3024 & n. a. \\
\hline \multirow{2}{*}{ FEM } & Hex8 & 0.2978 & $1.5 \%$ \\
\cline { 2 - 4 } & Hex20 & 0.3032 & $0.3 \%$ \\
\hline \multicolumn{2}{|c|}{ FVM } & 0.0347 & $88.5 \%$ \\
\hline
\end{tabular}

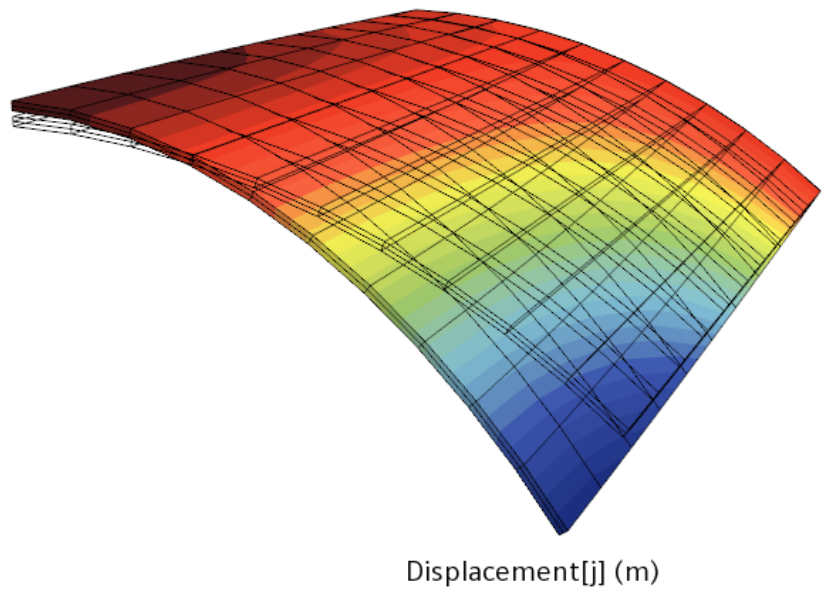
$-0.3002$
$-0.2313$
$-0.1624$
$-0.0935$
$-0.0247$
0.0442

Figure A.5. Vertical displacement of the roof modeled with Hex8 finite elements for case SM-2 (the deformation was scaled up to improve the readability of the figure). 


\section{Argonne}

Nuclear Science \& Engineering Division

Argonne National Laboratory

9700 South Cass Avenue, Bldg. 208

Argonne, IL 60439

www.anl.gov

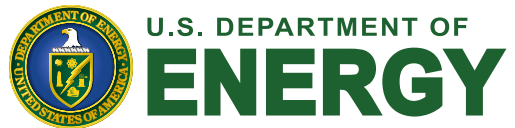

Argonne National Laboratory is a U.S. Department of Energy laboratory managed by UChicago Argonne, LLC 